\title{
Does Hope Moderate the Effects of Financial Distress in Adolescent Resiliency?
}

\author{
Miles E. Payne \\ mep0034@mix.wvu.edu
}

Follow this and additional works at: https://researchrepository.wvu.edu/etd

Part of the Educational Psychology Commons

\section{Recommended Citation}

Payne, Miles E., "Does Hope Moderate the Effects of Financial Distress in Adolescent Resiliency?" (2020). Graduate Theses, Dissertations, and Problem Reports. 7753.

https://researchrepository.wvu.edu/etd/7753

This Thesis is protected by copyright and/or related rights. It has been brought to you by the The Research Repository @ WVU with permission from the rights-holder(s). You are free to use this Thesis in any way that is permitted by the copyright and related rights legislation that applies to your use. For other uses you must obtain permission from the rights-holder(s) directly, unless additional rights are indicated by a Creative Commons license in the record and/ or on the work itself. This Thesis has been accepted for inclusion in WVU Graduate Theses, Dissertations, and Problem Reports collection by an authorized administrator of The Research Repository @ WVU. For more information, please contact researchrepository@mail.wvu.edu. 
Graduate Theses, Dissertations, and Problem Reports

2020

Does Hope Moderate the Effects of Financial Distress in Adolescent Resiliency?

Miles E. Payne

Follow this and additional works at: https://researchrepository.wvu.edu/etd

Part of the Educational Psychology Commons 
Does Hope Moderate the Effects of Financial Distress in Adolescent Resiliency?

Miles Payne

Thesis submitted to the

College of Education and Human Services

at West Virginia University

in partial fulfillment of the requirements

for the degree of

Master of Arts in

Educational Psychology with an emphasis in

Child Development and Family Studies

Kristin L. Moilanen, Ph. D., Chair

Jeffery Daniels, $\mathrm{Ph}$. D.

Aaron Metzger, Ph. D.

Department of Learning Sciences and Human Development

Morgantown, West Virginia

2020

Keywords: financial distress, hope, prosocial behavior, anxiety, adolescence

Copyright 2020 Miles Payne 


\section{ABSTRACT \\ Does Hope Moderate the Effects of Financial Distress in Adolescent Resiliency?}

Miles Payne

Little is known about the influence that hope may have on adolescent outcomes despite financial distress. This study considered financial distress as a risk factor in testing the moderating ability of hope on adolescent prosocial behavior and anxiety (PSB). Adolescents $(n=500)$ ranging from $11.00-16.00$ years of age completed in-home questionnaires two years apart. Results indicated a direct effect between PSB and hope. However, analyses revealed no moderated effects, as controlling for prior levels of PSB or anxiety accounted for most of the variance. Although hope may be beneficial to PSB, the stability from prior levels of each outcome washes out any direct effect from hope. Limitations and future directions are discussed. 


\section{Acknowledgments}

I recognize that this study would not be possible if not for the generous support of the Family Studies Center at BYU, the School of Family Life, and the College of Family Home and Social Science at BYU through the Flourishing Families Project. In particular, I would like to thank Dr. Padilla-Walker for her kind support for being the gateway for this study via the FFP. Furthermore, I would like to thank my community of friends and mentors in both TDT and my cohort. You all gave me strength, hope, and laughs when I struggled in and out of school. You all made this journey worth every step, thank you. Regarding the study itself, I am beyond grateful that the inspiration for asking about hope and resilience ultimately stems from my father and my faith. I would not be here without either. Lastly, I want to thank a fellow Michigander in my advisor, Dr. Moilanen, for her guidance, support, and mentorship throughout this work and my studies at West Virginia University. 


\section{Table of Contents}

Introduction 1

Justification for Study $\quad 4$

Literature Review $\quad 5$

Theoretical Approach $\quad 5$

Financial Distress as a Risk Factor That Threatens Resilience $\quad 10$

Hope as a Protective Factor That Supports Resilience $\quad 14$

$\begin{array}{ll}\text { Hope as a Moderator of Financial Distress } & 17\end{array}$

$\begin{array}{ll}\text { Control Variables } & 19\end{array}$

$\begin{array}{ll}\text { The Current Study } & 20\end{array}$

$\begin{array}{ll}\text { Hypotheses } & 21\end{array}$

$\begin{array}{ll}\text { Methods } & 22\end{array}$

$\begin{array}{ll}\text { Participants } & 22\end{array}$

Measures \& Procedures $\quad 23$

$\begin{array}{ll}\text { Analysis Plan } & 25\end{array}$

$\begin{array}{ll}\text { Results } & 27\end{array}$

$\begin{array}{ll}\text { Discussion } & 34\end{array}$

Strengths, Limitations, \& Future Directions 39

Conclusion \& Implications $\quad 44$

$\begin{array}{ll}\text { References } & 48\end{array}$

$\begin{array}{ll}\text { Appendix A } & 62\end{array}$

$\begin{array}{lc}\text { Appendix B } & 63\end{array}$

$\begin{array}{lr}\text { Appendix C } & 64\end{array}$ 
Appendix D

Appendix E

Appendix F

List of Tables

Figures 
DOES HOPE MODERATE THE EFFECTS OF FINANCIAL DISTRESS

\section{Chapter I}

\section{Introduction}

Adolescence has historically been characterized as a time of storm and stress (Steinberg \& Lerner, 2004). Although this historical perspective has been continuously debunked, adolescence is still a period of significant vulnerability to mental health complications (Belfer, 2008). A recent study has shown that a potential cause of these complications and the exacerbation of others could be because of an individual's financial status (Russell \& Odgers, 2020). Since adolescence is such a crucial period of life with the potential to cultivate various positive and negative outcomes (Padilla-Walker, Hardy, \& Christensen, 2011), the influence of financial distress (FD) and its ability to affect adolescent outcomes cannot be overlooked (McLoyd, Kaplan, Purtell, Bagley, Hardaway, \& Smalls, 2009).

As research has inquired into the positives and negatives of the adolescent experience, many of these explorations do not address how the inclusion of protective factors may influence the process of how adolescents overcome negative experiences. The literature that has sought to describe this process of flourishing and overcoming negative experiences refers to this process as resiliency. Resilience is a process where positive outcomes arise despite major adversity to adjustment or development (Masten, 2001). Resiliency is a phenomenon that is accessible to every individual and is a process that could happen within any particular day. This process, although being entirely common and prevalent in people's lives, has been historically understudied (Masten, 2001). Therefore, with much of recent research taking a positive youth development (PYD) perspective (Callina, Johnson, Buckingham, \& Lerner, 2014), research has also taken on the challenge of understanding resiliency in adolescence. Research has posed new questions about development, such as, how we can not only study the maladaptive aspects of 


\section{DOES HOPE MODERATE THE EFFECTS OF FINANCIAL DISTRESS}

adolescence but how can we focus on the ways that adolescents develop positively? More so, how may we better understand youth that do develop positively despite adversity?

If we are to understand positively developing youth despite adversity, then we must highlight the role that resiliency and its three main components play. For resiliency to occur, there must first be the presence of a risk factor (Zimmerman, Stoddard, Eisman, Caldwell, Aiyer, $\&$ Miller, 2013). A risk factor is a predictor of an undesirable outcome through its relationship with a higher probability of negative development (Masten, 2001). The second factor in resilience theory is that there must be one or more promotive factors (Fergus \& Zimmerman, 2005). A promotive factor is an asset or a resource that works against risk factors by promoting positive development instead of protecting against the exposure to negative influences (Zimmerman, 2013). An asset is within the adolescent (e.g., self-efficacy), while resources are external to them (e.g., parental support; Zimmerman, 2013). Third, an adolescent's resiliency must be measured through a negative or positive outcome that must be stable or improve since the exposure to risk (Kumpfer, 2002). The positive outcomes that arise despite adversity can be sudden, gradual, or oscillate (Fergus \& Zimmerman, 2005). Therefore, and in addition to these three main components of resilience, a vital determinant of the process is that adolescents do not develop maladaptive traits as a result of their risk exposure (Masten, 2001). For resilience to be present, there must be positive development despite a high-risk environment (Fergus \& Zimmerman, 2005). These three tenets of resiliency framework will be explored later in the literature review in addition to the specific factors for this study.

For this study, the risk that is being examined is the adolescent's exposure to FD. FD is the perceptions of an adolescent's or a family's economic stability and the pressure felt by the uncertainty around making financial ends meet (Conger, Elder, Lorenz, Simons, \& Whitbeck, 


\section{DOES HOPE MODERATE THE EFFECTS OF FINANCIAL DISTRESS}

1992). In this study, the process of hope is the focal promotive factor. Hope is "the feeling that what is wanted can be had or that events will turn out for the best" (dictionary.com). Promotive factors such as hope would operate by moderating the relationship between the risk variable and the outcomes. For this study, prosocial behaviors (PSB) and anxiety will be the outcomes. PSB are the intentional actions that an individual does to foster a positive outcome for a given recipient, regardless of the outcome to themselves (Grusec, Davidov, \& Lundell, 2002). Examples include generosity, sharing, reciprocity, and cooperation (Thielmann, Spadaro, \& Balliet, 2020). Anxiety is a future-oriented mood characterized by an individual's preoccupation with the possible arrival of adverse events, which causes fear from the real or perceived danger of those events (Craske, Rauch, Ursano, Prenoveau, Pine, \& Zinbarg, 2009). The goal of this study is to discover if hope moderates the relationships between FD and PSB and anxiety. Ideally, a resilient individual in this context would exhibit higher levels of PSB and lower levels of anxiety, even with the presence of FD. If the inclusion of hope results in higher levels of PSB in addition to lower levels of anxiety, this would provide reasonable justification for concluding that hope is a factor of resiliency.

In the current developmental research, the focus around positive youth development has neglected to include hope as a promotive factor for resilience. There is research that shows hope to be positively related to adolescents' positive outcomes, such as higher school engagement, lower delinquency, and fewer internalizing behaviors (Padilla-Walker et al., 2011). High levels of hope also correlate highly with adolescents' life satisfaction (Valle, Huebner, \& Suldo, 2004). Furthermore, higher levels of hope often correlate with high adolescent levels of self-esteem (Snyder, Cheavens, \& Sympson, 1997). However, no research explicitly connects how hope may moderate the effects of FD as they lead to anxiety and PSB. Specifically, how does the presence 
DOES HOPE MODERATE THE EFFECTS OF FINANCIAL DISTRESS

of hope in an adolescent's life allow them to mitigate FD and develop healthily?

\section{Justification for the Study}

The justification for this study lies within the fact that other studies on hope have called for research to continue clarifying how hope may influence developmental outcomes (Arnau, Rosen, Finch, Rhudy, \& Fortunato, 2007; Ng, Lam, \& Chan, 2017). Although there are a few studies that have shown associations between hope and PSB and anxiety, the literature has yet to make explicit connections between the unique combination of how FD and adolescent's hope as they lead to PSB and anxiety. Exploring this connection is novel and may provide the conceptual basis for future research by showing validation and support for hope as a buffering factor for resilience. This information may inform interventions, community programs, and academic communities to the importance of fostering hope in the youth. 
DOES HOPE MODERATE THE EFFECTS OF FINANCIAL DISTRESS

\section{Chapter II}

\section{Literature Review}

\section{Theoretical Approach}

For the present study, the theoretical framework is resilience theory. This theory is described by three major tenets required to justify a developmental process as being resilient (Fergus \& Zimmerman, 2005). Beyond describing the factors that contribute to understanding of what resilience is, I will also add further depth to the theoretical framework by explaining how hope may act as a moderator by examining hope theory. These models are discussed below.

Resilience theory. Resiliency is the framework for this study, in which I recognize resiliency as a process rather than a trait or outcome (Luthar, Cicchetti, \& Becker, 2000). From this perspective, for resilience to occur, the process must represent how an individual combats risk through activating a promotive factor rather than reducing the initial presence of adversity (Zimmerman et al., 2013). Other scholars have treated resilience as a trait, meaning that resiliency is a personality dimension or attribute. For example, early studies of resilience focused on certain qualities of resilient individuals like autonomy or self-esteem (Luthar et al., 2000). However, it is imperative to note the implications of this view. Treating resilience as a trait sets a precedent that for some adolescents, their better adjustment relative to their peers, is predetermined. Therefore, adolescents who do not have this resilience are similarly predetermined for difficulties because of an inherent trait not amenable to intervention (Masten, 1994). Subscribing to the trait perspective is contrary to the fundamental belief of developmental scholars that interventions are necessary for vulnerable populations for positive social change (American Psychological Association, 2017). Other scholars have also treated resilience as an outcome, meaning resilience is a positive accumulation of various developmental markers of 


\section{DOES HOPE MODERATE THE EFFECTS OF FINANCIAL DISTRESS}

high-risk individuals (Luthar et al., 2000). In addition to differing perspectives over the conceptual nature of resilience, there is also discussion over which risk factors and promotive factors are associated with resiliency. Examples of risk factors may be family health history, SES, or traumatic accidents while examples of promotive factors may an individual's cultural history, biology, familial system, or psychology (Masten, 2001; Southwick, Bonanno, Masten, Panter-Brick, \& Yehuda, 2014). Even though studies from these different perspectives have differed in their conceptualization of which risk and promotive factors feed into resiliency, they still yield concurrent empirical findings that point to resiliency as a strengths-based approach made of three common factors (Masten, 2001).

As summarized above, the first of the three required components is that a risk factor must be present (Fergus \& Zimmerman, 2005). An example of a risk factor is the accumulated stress represented by FD (Conger, Ge, Elder, Lorenz, \& Simons, 1994), and this study will question whether adolescents can be resilient despite FD. Understanding the influence that FD has on adjustment is critical to further explaining how FD creates the adverse environment required in the resiliency theory framework. The second is that a form of a promotive variable (e.g., resources or assets) that is linked to better outcomes must be present (Masten, 2001). Associations between hope and adolescent outcomes like higher school engagement, fewer internalizing behaviors, and lower delinquency, suggest that hope can act as a promotive factor for resiliency (Padilla-Walker et al., 2011). Lastly, an individual's outcome must remain stable if not improve with the presence of the promotive factor against the risk exposure (Kumpfer, 2002). Thus, the present study examined this in terms of rank-order changes over two years in PSB and anxiety. 
DOES HOPE MODERATE THE EFFECTS OF FINANCIAL DISTRESS

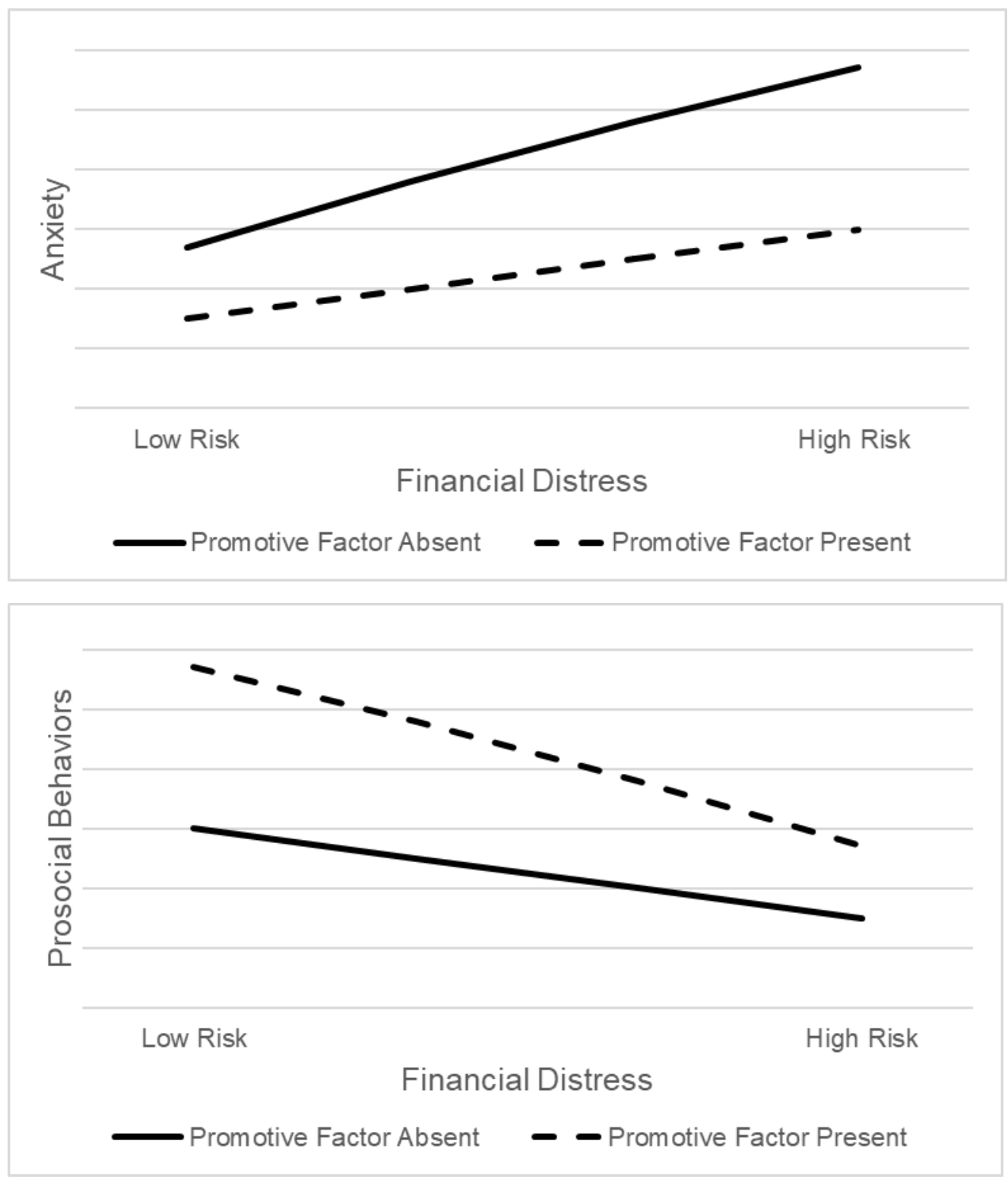

Figures $1 a-b$. The Protective Reactive Model for a positive outcome and a negative outcome (Fergus \& Zimmerman, 2005).

The resiliency process can follow several patterns. I predict that in this context, it will take a shape that is congruent with the protective-reactive model, as described by Fergus and Zimmerman (2005). This model stipulates that the presence of a buffer or promotive factor will alter the severity of the risk factor's influence on adjustment outcomes (i.e., the promotive factor 


\section{DOES HOPE MODERATE THE EFFECTS OF FINANCIAL DISTRESS}

of hope will mitigate the risk conferred by FD for PSB and anxiety). To elaborate, the protectivereactive model is best understood visually if the measured outcomes are placed along $\mathrm{X}$ and $\mathrm{Y}$ axes (see Figures 1a and 1b).

The $\mathrm{X}$-axis represents the variation in the levels of the risk factor. The $\mathrm{Y}$-axis represents the variation in the degree of outcomes. In theory, without the promotive factor, the development of adverse outcomes would increase as the presence of risk increases. For example, highly financially distressed adolescents are at a greater risk for lower academic achievement (Leung \& Shek, 2011). One avenue that adolescents could seek to help alleviate their poor academic performance is through academic tutoring. Tutoring as a promotive factor may teach adolescents academic skills that may increase their academic performance. Although tutoring may promote academic achievement, it will not negate the insidious effects of FD, which will still influence other parts of adolescent development (Leung \& Shek, 2011). Thus, per this model, it is predicted that PSB will be higher, and anxiety will be lower with the presence of high levels of hope than in comparison with low levels of hope. Hope may not completely mitigate the harmful effects of FD for PSB and anxiety. However, it may reduce the degree of adverse outcomes and promote the degree of positive outcomes rather than reducing the presence of FD itself.

In the absence of data about these associations, it is difficult to predict which pattern of resilience will provide the best fit. However, the general pattern in literature is consistent with the protective-reactive model in which promotive factors usually lessen but do not entirely erase the predicted associations between risk factors and the outcomes at question (Fergus \& Zimmerman, 2005). Rather, promotive factors will alleviate the risk factor's impact on adjustment which is consistent with the hypothesized protective-reactive model. 


\section{DOES HOPE MODERATE THE EFFECTS OF FINANCIAL DISTRESS}

Hope theory. The research on hope in adolescence has shown it to be an internal construct and a promotive factor (Arnau et al., 2007). Snyder and colleagues (1991) pioneered a strengths-based conceptualization of hope. They defined it as "a positive motivational state that is based on an interactively derived sense of successful (a) agency (goal-directed energy), and (b) pathways (planning to meet goals)" (Snyder, 2002, p. 250). Essentially, hope is a motivational process consisting of two primary parts. First, goal orientation involves constructing a clear and concise goal that an individual wants to accomplish (Snyder, 2002). For example, if an adolescent wanted to make new friends, then the creation of those new friendships would be the goal. Secondly, and after the goal is established, individuals would continue to hope by engaging in the aforementioned pathways and agency. The pathways are the progressive and perceived capabilities the adolescent can plan and utilize that will move them closer to their goal (Arnau, 2018). An adolescent wanting to make new friends may incrementally start conversations or share a snack with their peers to foster familiarity and find common likes and interests. In addition to pathways, agency would be the belief in themselves that they have the ability to actualize a goal. However, an adolescent's agency must be coupled with pathways to exercise that agency, making both unique and equal components of hope (Snyder, 2002). Thus, the adolescent must not only have the desire to develop relationships with peers but have the skillset and ability to do so.

For further examples of hope in context, volunteering is one example of prosocial behavior. Within the hope theory framework, the goal aspect is first to identify volunteering as an action worth doing and to cultivate a desire to do it. With volunteering as the goal, adolescents must then utilize the agency aspect of hope theory by framing volunteering as an activity that can and should be done. Lastly, they must engage their perceived capabilities as 


\section{DOES HOPE MODERATE THE EFFECTS OF FINANCIAL DISTRESS}

pathways to move towards the goal of volunteering. This might be learning about resources at school or local agencies that host volunteering events.

Another example of hope in context is adolescent test anxiety. Within hope theory, the adolescent's goal is to establish their desire to do well on their upcoming test. After having a clear set target, the adolescent must cultivate a sense of agency of their ability to do well on the test because they have the skills and knowledge obtained through their studying. Lastly, they must forge and utilize their perceived capabilities as the pathways to doing well on the exam. This may be through tapping into their confidence by self-talk or remembering test-taking strategies that assist them in performing well.

Regardless of whether the obstacle facing the adolescent is volunteering or test anxiety, empirical work shows that high hope-oriented individuals are more likely to overcome these than are their low hope counterparts (Chang \& DiSimone, 2001). Research shows that high hope individuals' ability to overcome is through their high sense of agency. Their goal did not change, and as obstacles arose, high hope individuals drew upon their agency and adjusted their progressive steps to maintain their work towards the goal while accounting for the obstacles (Valle, Huebner, \& Suldo, 2006). Prior research supports the notion that hope may be a buffer and may help individuals demonstrate resilience since hope can act as a protective factor that offsets or buffers the effects of risk factors (Valle et al., 2006). Therefore, hope could be an integral piece in understanding how adolescents are resilient against FD.

\section{Financial Distress as a Risk Factor That Threatens Resilience}

Definitions. Research has often used SES to understand families' economic situations. However, this study will utilize the term "financial distress". SES has been previously conceptualized through educational attainment, parental employment status, and household 


\section{DOES HOPE MODERATE THE EFFECTS OF FINANCIAL DISTRESS}

income. While FD is distinct because rather than the amount of income a family may have, the parents' perceptions of a family's economic stability and the pressure felt by the uncertainty around making financial ends meet determines their stress (Conger et al., 1992). The literature supports the conclusion that low SES families are more likely to be high in FD. In one study, high FD was associated with lower levels of SES (Reyes \& Yujuico, 2014). Nevertheless, FD can affect different families in different ways. For example, a family of three with an income slightly above the poverty line may have a high degree of FD from an accumulation of medical bills and housing costs. Conversely, a family of four below the poverty line may have a low degree of FD due to good health and lack of debt. In sum, it is crucial to recognize the subjective stress that a family may experience because of their finances regardless of their real income. Thus, throughout the literature review, I will discuss evidence that utilizes both SES in addition to FD as they relate to adolescent resilience.

Financial distress and adjustment. FD connects to poor adjustment in adolescence, specifically to poor mental health, low educational achievement, low future orientation, and high delinquency (Leung \& Shek, 2011; McLoyd et al., 2009). Additionally, adolescent girls' internalizing and externalizing behaviors are directly related to family financial hardship (Lehman \& Koerner, 2002). FD is also positively associated with adolescent substance abuse (Conger, Lorenz, Elder, Melby, Simons, \& Conger, 1991). Furthermore, FD is directly connected to an adolescent depression-loneliness distress factor (Lempers, Clark-Lempers, \& Simons, 1989). In sum, FD is an evident influence in overall adolescent adjustment.

Associations between FD and global adolescent adjustment may be attributed to any of several processes, which include but are not limited to family functioning and individual cognitions (Blum \& Blum, 2009). Regarding family functioning, families who differ in their 


\section{DOES HOPE MODERATE THE EFFECTS OF FINANCIAL DISTRESS}

level of FD interact differently with one another (Prawitz, Kalkowski, \& Cohart, 2013). Families who report high levels of distress have higher reported familial anger, frustration, and parentchild conflict than do families with low distress (Elder \& Caspi, 1988). Conversely, adolescents in less financially distressed families report healthier family functioning (Georgiades, Boyle, Jenkins, Sanford, \& Lipman, 2008). Overall, high levels of parent-child conflict associated with high FD may pave the way for problems with physical health and academic competence in adolescence (Conger, Conger, \& Martin, 2010). In sum, FD may impact adolescent development through the interpersonal dynamics within the family.

Regarding individual cognitions, a proposed explanation is that adolescents may combat the effects of FD by utilizing active coping skills like problem-solving and being hopeful (Allen et al., 2016). Conversely, adolescents' developmental outcomes may be impeded if they are not able to regulate themselves effectively due to spillover from family stress (Benson, Buehler, \& Gerard, 2008). Hypothetically, resilient adolescents would resist spillover from external stressors through various promotive factors such as the previously mentioned active coping and being hopeful (Allen et al., 2016). In contrast, nonresilient adolescents may fail to counteract this spillover via self-blame, instead of crediting these stressors to societal and systemic inequality (Shek, 2004). These proposed explanations of individual cognitions, such as active coping, being hopeful, or self-blame, aim to explain how adolescents react to FD as a definite source of adversity to overcome.

Financial distress and prosocial behaviors. To date, no known evidence explicitly links FD and PSB in adolescence. However, prior to adolescence, there is some evidence of this phenomenon through a study of three-year-old children and their mothers in Zambia, which revealed that when mothers reported high perceived FD, their children were less likely to be 
DOES HOPE MODERATE THE EFFECTS OF FINANCIAL DISTRESS

prosocial towards other children (Chernyak, Harvey, Tarullo, Rockers, \& Blake, 2018). Thus, a similar pattern is expected for adolescents. A potential reason for the lack of direct evidence in adolescence may be because the overall impact is indirect in nature. For example, in one study, FD predicted parent depressive symptoms, and that association impacted the parent-child connection and thus led to lower levels of the child's PSB (Carlo et al., 2011). Through parent stress or depressive symptoms, FD can ultimately impact adolescent PSB though parent stress, hostility, or depressive symptoms (Carlo et al., 2011; Chernyak et al., 2018). Therefore, the current study attempts to provide evidence as to whether FD may impact adolescent prosocial behavior.

Financial distress and anxiety. In contrast to the scanty literature on FD and adolescent PSB, there is slightly more research to show an association between FD and anxiety. However, the support for this evidence primarily comes from studies on adults. For example, a study of about 3000 adults between 18-65 years of age found an association of high degrees of FD with high degrees of anxiety (Dijkstra-Kersten, Biesheuvel-Leliefeld, Wouden, Penninx, \& Marwijk, 2015). Wilkinson (1999) also found that lower SES is related to higher levels of anxiety in adults. Furthermore, high levels of FD are also significantly correlated with high levels of anxiety in college students (Assari, 2018). Lastly, 180 Midwest college students who reported higher levels of financial satisfaction also reported lower levels of financial anxieties (Archuleta, Dale, \& Spann, 2013). Therefore, there is research to support the association between FD and anxiety in adulthood, but it is unknown whether there are parallel associations in adolescence. It is expected that the association between FD and anxiety in adolescence would be comparable to what we know about older populations. 


\section{DOES HOPE MODERATE THE EFFECTS OF FINANCIAL DISTRESS}

In addition to the general mechanisms discussed above, the anxiety literature contains additional hypothetical explanations as to how and why these associations may exist. One explanation is through social comparisons. When an individual compares their financial state against others within their social context, they may discover the different opportunities afforded by different financial situations. Therefore, as a teen questions their financial state in comparison to others, this may cause anxiety. This behavior is typical within adolescence as numerous studies have shown how youth may compare their family's financial situation to their peers' family situations (Ng et al., 2017; Reyes \& Yujuico, 2014; Shek, 2004). Although most studies about FD and anxiety are through adults, adolescents are similarly likely to experience anxiety because of FD.

\section{Hope as a Protective Factor That Supports Resilience}

Definition. As noted earlier, hope is commonly understood as a belief that what is desired can be achieved. Hope has also been operationalized as a motivational state with two main mechanisms (Snyder, 2002). An individual must define a goal to pursue, cultivate a sense of agency that empowers them to believe they can reach that goal, and enact pathways to make progress towards the goal. For example, a study has shown that an individual with a high level of hope would have a strong orientation towards their goal and a high degree of agency (PadillaWalker et al., 2011). In sum, individuals with high levels of hope should be able to navigate the obstacles in pursuit of their goal.

Hope and adjustment. Previous research has shown that hope can have a strong influence on adjustment in adolescence. Hope has been directly linked to subjective well-being (Vacek, Coyle, \& Vera, 2010). Further, high levels of hope can act as a psychological strength that allows for adaptive coping (Horton \& Wallander, 2001; Valle, Huebner \& Suldo, 2006), 


\section{DOES HOPE MODERATE THE EFFECTS OF FINANCIAL DISTRESS}

which means that hope can be a tool that adolescents use to adjust positively to new stressors. Consistent with this notion, one study in adolescence noted that high levels of hope correlated with higher levels of life satisfaction in addition to lower levels of internalizing and externalizing behaviors (Valle et al., 2004). Further, hope is significantly related to higher levels of academic achievement and school engagement (Bryce, Alexander, Fraser, \& Fabes, 2020; Buckelew, Crittendon, Butkovic, Price, \& Hurst, 2008). Hope may be a key component in promoting positive development despite an adverse event or environment. A study of 1,273 4-H youths found further support that hope may influence positive development (Schmid, Phelps, Kiely, Napolitano, Boyd, \& Lerner, 2011). They found that high hope for the future was significantly linked to high levels of intentional self-regulation. Furthermore, the youth indicated that higher levels of hope led them to engage in more active coping strategies. Therefore, this study further suggests that the increase of active coping because of high levels of hope may lead to fewer emotional or behavioral problems (Allen et al., 2016). In sum, hope has a clear and defined association with adolescent adjustment.

Hope and prosocial behaviors. Some literature shows a positive association between hope and PSB. For example, multiple studies reported a positive correlation between children's hope and their PSB (Padilla-Walker et al., 2011; Xiang, Cao, Yin, \& Liu, 2016). There are multiple proposed explanations as to how hope may be related to PSB. The first proposed explanation is through social skills and motives. In general, hope is a strength that can help adolescents cultivate relationships with peers (Little, Snyder, \& Wehmeyer, 2006). If an adolescent had a goal of developing a relationship with a peer, then they will need to engage in PSB to cultivate the relationship. However, an adolescent lacking the social skills or knowledge to engage in PSB to cultivate the relationship may be impeded by a lack of confidence or self- 


\section{DOES HOPE MODERATE THE EFFECTS OF FINANCIAL DISTRESS}

efficacy (Staub, 1995). There is empirical support that shows adolescents who have high hope may overcome any lack of self-efficacy through agentic thinking to engage the social skills needed for PSB (Padilla-Walker et al., 2011). Therefore, hope may influence PSB by helping adolescents overcome a lack of social skills by giving them the confidence and agency to offer help to another person.

A second proposed explanation is that high hope adolescents may have an incentive to try and raise the amount of hope in their peers. High hope adolescents are hypothetically more likely to believe there is a connection between their level of hope to others' level of hope (Rand \& Cheavens, 2009). Therefore, adolescents have an incentive to use PSB to address and try to increase others' degrees of hope because helping another's level of hope would, in turn, raise their level of hope (Rand \& Cheavens, 2009). This proposed explanation aligns with other explanations that high hope individuals may adapt to and embrace others' goals if doing so is advantageous to achieving their original goal (Nolan \& Stitzlein, 2011; Padilla-Walker et al., 2011). Although there are multiple proposed explanations for the relationship between hope and PSB, there is still a lack of clarity of the relationship in adolescent literature.

Hope and anxiety. Contrary to PSB, the connection between anxiety and hope in adolescence is supported by far more research. Multiple studies have found that higher levels of hope correlate with lower levels of anxiety (Arnau et al., 2007; DiPierro, Fite, \& JohnsonMotoyama, 2018; Yeung, Ho, \& Mak, 2015). Previous scholars have argued that hope and anxiety have a clear association because there is a positive motivational component to hope in a similar way that there is a negative motivational component to anxiety (Arnau, 2018). In general, anxiety is a mindset of the inability to act due to feelings of vulnerability, lack of control, and unpredictability (Barlow, 2000). Thus, the connection between hope and anxiety is through the 


\section{DOES HOPE MODERATE THE EFFECTS OF FINANCIAL DISTRESS}

ability to act towards goals and adapting through obstacles. In other words, hope utilizes agency to act towards a goal (Snyder, 2006), but anxiety is a mindset of inability to act towards goals (Barlow, 2000). Further, hope is about adapting to obstacles to reach a goal instead of a lack of control commonly found in anxiety. Thus, it is a logical conclusion that hope would negatively correlate with anxiety (Michael, 2000).

\section{Hope as a Moderator of Financial Distress}

Scholars are continuing to understand how FD both directly and indirectly influences psychological adjustment in adolescence. As more studies uncover these relationships, it is vital to the field that the mechanisms that may moderate the degree of impact are also understood. Hope, as presented by Snyder et al. (1991), may play a significant role in moderating the effects that FD can have on adolescent development. Although empirical data indicate that hope correlates with anxiety and PSB, no research was found that explicitly examines how hope may moderate the influence that FD has on PSB, anxiety, or any other adjustment-related outcome in adolescence or adulthood.

Regarding FD, there is empirical support to suggest that the effects of risk factors such as FD on adjustment-related outcomes are moderated by other comparatively proximal factors. For example, parent-youth relationship moderated the association between parental FD due to unemployment and adolescent emotional distress (Frasquilho, de Matos, Marques, Neville, Gaspar, Caldas-de-Almeida, de Matos, Neville, \& Caldas-de-Almeida, 2016). In other words, the parent-youth relationship exacerbates the link between parental FD and negative adolescent emotional distress. Another example is that social cohesion moderated the relationship between FD and psychological distress for residents aged 16 years and older (Erdem, Van Lenthe, Prins, Voorham, \& Burdorf, 2016). There was a weaker link between psychological distress and FD 


\section{DOES HOPE MODERATE THE EFFECTS OF FINANCIAL DISTRESS}

with high levels of social cohesion. In other words, social cohesion buffered the effects that FD has on physiological distress (Erdem et al., 2016). Lastly, self-efficacy also moderated the connection between FD and psychological distress in adults (Selenko \& Batinic, 2011). The study results showed that high levels of self-efficacy mitigated the connection between FD and mental health. Overall, empirical research has shown how adjustment related to FD may be influenced by various factors in different populations. However, the impact of mitigating factors on adolescent FD-related adjustment remains unclear.

Hope has also been explored as a moderator in adolescence for various other risk factors and outcomes. For example, hope moderated the influence of depressive symptoms on adolescent girls' nonsuicidal self-injury (Jiang, Ren, Liang, \& You, 2018). However, the buffering effect was relatively weak in that the association between depressive symptoms and nonsuicidal self-injury stayed significant even at higher levels of hope. Hope also moderated the effect of tobacco and marijuana use on adolescent delinquent behavior (Fite et al., 2014). Although research has progressed in understanding how hope may moderate various outcomes in other forms of adjustment, it remains to be seen how hope may moderate the effects of FD on PSB and anxiety in adolescence.

I expect the results of this study to show similar results of the moderated effects of FD and the moderating potential of hope, in comparison to previous studies. For example, Prawitz et al. (2013) found that families reporting high levels of FD were also likely to report low levels of hope. Recent research has also shown that in a study with high and low hope groups, high SES families were more likely to belong to the high hope group as compared to low SES families (Yin, Li, Yuan, \& Wang, 2019). Therefore, since there is evidence of the connection between 


\section{DOES HOPE MODERATE THE EFFECTS OF FINANCIAL DISTRESS}

hope and FD, this study seeks to understand how that connection may intertwine and relate to PSB and anxiety among adolescents.

It is expected that hope will have a small but significant moderating effect. When adolescents have high levels of hope, the relationship between FD and anxiety will be weak and vice versa regarding low levels of hope. Additionally, when adolescents have high levels of hope, it is expected that the relationship between FD and PSB will be strong and vice versa regarding low levels of hope.

\section{Control Variables}

The present study included sex, race, age, and SES as control variables. Research has shown that regarding PSB and sex, girls tend to be more prosocial (Fabes, Carlo, Kupanoff, \& Laible, 1999). Regarding PSB and race, white adolescents tend to have higher levels of PSB than youth of color (Voight, Geller, \& Nation, 2014); however, adolescents of color may also have high PSB depending on the racial makeup of their peers (Wentzel, Filisetti, \& Looney, 2007). Regarding PSB and age, adolescents tend to increase or remain stable across adolescence, except for PSB towards strangers declining during the transition to adulthood (Padilla-Walker, Carlo, \& Memmott-Elison, 2018). PSB has been shown to be related to SES (Reyes \& Yujuico, 2014). Although older literature has shown that lower SES adolescents have higher levels of PSB (Knight \& Kagan, 1977), current research has shown that lower SES adolescents exhibited lower levels of PSB (Simões, Calheiros, \& Alarcão e Silva, 2018). Prior PSB may also influence later PSB. Multiple studies using the same Flourishing Families Project dataset as this study have found that adolescents who display high levels of PSB are likely to display high levels of PSB later (e.g., Padilla-Walker et al., 2018; Padilla-Walker, Carlo, \& Nielson, 2015). However, other 


\section{DOES HOPE MODERATE THE EFFECTS OF FINANCIAL DISTRESS}

studies also find stability in prosocial behaviors in adolescence (e.g., Eisenberg, Guthrie, Murphy, Shepard, Cumberland, \& Carlo, 1999).

Research has shown that generalized anxiety is more likely to be experienced by girls (Ohannessian, Cavanaugh, \& Cheeseman, 2017). For race/ethnicity, one study found no racial differences in clinical anxiety (Gordon-Hollingsworth et al., 2015) Caucasian adolescents are the least likely to experience anxiety in comparison to other racial minority adolescents (Okamura, Ebesutani, Bloom, Higa-McMillan, Nakamura, \& Chorpita, 2016). Regarding age, anxiety tends to be higher during mid-adolescence than early adolescence (Copeland, Angold, Shanahan, \& Costello, 2014). High levels of adolescent anxiety are related to low SES (Sancakğlu \& Sayar, 2012). Prior anxiety may also influence later anxiety. Other studies using the same FFP dataset as this study have found that adolescents who have high levels of anxiety are likely to have high levels of anxiety later (Coyne, Stockdale, \& Summers, 2019. However, other studies using different data sets have also found stability in anxiety (Bosquet \& Egeland, 2006; Letcher, Sanson, Smart, \& Toumbourou, 2012). Therefore, research to date shows that anxiety tends to be stable during adolescence.

\section{The Current Study}

Current research has neglected to answer how the specific outcomes of PSB and anxiety in adolescents who face FD may related to hopefulness. Therefore, this study's focus is to uncover the direct relationship that FD has with PSB and anxiety in adolescents and how the level of hope in an adolescent may moderate that relationship. However, without the presence of hope, it is predicted that adolescents who are high in FD will have low levels of PSB and high levels of anxiety. Further, I hypothesize that adolescents who are low in FD will have high levels of PSB and low levels of anxiety. 
DOES HOPE MODERATE THE EFFECTS OF FINANCIAL DISTRESS

With hope included as a moderator, I expect that despite FD, high levels of hope will promote PSB after controlling for initial levels of PSB. Furthermore, it is similarly expected that despite FD, hope will protect against anxiety, after controlling for initial levels of anxiety. Lastly, I predict that adolescents who are higher in FD will have lower levels of hope.

\section{Hypotheses}

H1: Adolescent girls will have higher levels of PSB than boys.

H2: High SES adolescents will have higher levels of PSB than low SES adolescents.

H3: Girls will have higher levels of anxiety than boys.

H4: Mid-adolescent aged adolescents will have higher levels of anxiety than younger aged adolescents.

H5: African American adolescents will have higher levels of anxiety than white adolescents. H6: Low SES adolescents will have higher levels of anxiety than high SES adolescents.

H7: High levels of FD will correlate with low levels of PSB and hope and with high levels of anxiety.

H8: High levels of hope will correspond to high levels of PSB and low levels of anxiety.

H9: The relationship between FD and PSB will be strong with high levels of hope.

H10: The relationship between FD and anxiety will be weak with high levels of hope. 
DOES HOPE MODERATE THE EFFECTS OF FINANCIAL DISTRESS

\section{Chapter III}

\section{Method}

\section{Participants and Procedures}

Data from the Flourishing Families Project (FFP) was used to address the present study's research questions. Researchers at Brigham Young University originally conducted the FFP starting in 2007, studying families with at least one child between the ages of 10 and 14 . The project originally had a sample of $N=500$ children $\left(M_{\text {age }}=11.29, S D=1.01,56 \%\right.$ female, $65 \%$ white American). Waves 3 and 5 provided the data for the current study.

The participants utilized in this study were/are geographically located in or near a major northwestern city of the United States. The participants of the study were randomly selected to match specific census data to represent the surrounding area's racial and economic diversity based on reports from the local high schools. They were first invited to participate via a telephone directory database (Polk Directories/InfoUSA). Each family was deemed eligible for the whole project (including and the following waves used for this study) if there was a child present between the ages of 10 and 14 (Padilla-Walker, Harper, \& Bean, 2011). Adolescent participants were contacted via a multistage recruitment protocol. In sum, 692 families were found to be eligible from the Polk Directory. Out of those families contacted to participate in Wave $1,61 \%(n=423)$ participated. However, to further match the overall demographics of the area, additional families were recruited to reach a total of $500(n=77,15 \%)$ participating in Wave 1. The additional 77 families were reached primarily through referrals, but fliers $(n=15)$ were also used. Once eligibility was established with the families, a team of interviewers made appointments for an in-home visit with each family. For the in-person visit, interviewers videotaped the interactions which consisted of video interviews - which are not relevant to this 


\section{DOES HOPE MODERATE THE EFFECTS OF FINANCIAL DISTRESS}

study - and member-specific questionnaires for the mother, father, and child (Lee, PadillaWalker, \& Memmott-Ellison, 2017).

After the initial demographics were collected, families were then contacted via phone. On the phone call, the research assistant would ask them to complete an online survey, gather the appropriate email addresses, inform the families of their compensation from completing the survey, and that the survey should be taken over one session of 45 minutes. A separate survey was sent for each family member (i.e., father, mother, and child).

\section{Measures}

Financial distress. This measure was drawn from the Family Transitions Project (Spilman \& Burzette, 2006), and was used to assess the FD of the family at Wave 3. For this study, the primary parent reported how much the statement applied to them with lower scores reflecting fewer financial concerns (e.g., "I have trouble sleeping because of my financial problems."). Adults responded to 13 items on a five-point Likert scale ranging from 1 (strongly disagree) to 5 (strongly agree). The alpha at Wave 3 was .91, indicating good internal consistency. Survey questions pertaining to FD can be found in Appendix A. These responses were averaged to create an index in which high scores correspond to high levels of FD.

Hope. The study's moderating factor was measured using questions derived from the Hope/Optimism Scale at Waves 3 and 5 (Peterson \& Seligman, 2004). For this study, teens reported how much they felt the statement was like them, and items were reverse-scored so that lower scores indicated higher levels of hope (e.g., "I expect the best" and "I know that I will succeed with the goals I set for myself"). Teens answered ten items on a five-point Likert scale ranging from 1 (very much like me) to 5 (very much unlike me). The measure's alpha level of .84 for hope at Wave 3 indicating good internal consistency. Survey questions pertaining to hope can 


\section{DOES HOPE MODERATE THE EFFECTS OF FINANCIAL DISTRESS}

be found in Appendix B. Survey responses were averaged to create a single score in which low scores were an indicator of higher levels of hope.

Prosocial behavior (PSB). Peterson and Seligman's Inventory of Strengths (2004) was used to measure PSB at Waves 3 and 5. For this study, teens reported how much the statement was like them with the higher the score the more PSB the individual engaged in towards others (e.g., "I help my friends, even if it is not easy for me" and "I enjoy being kind to my friends"). Participants answered 18 items on a five-point Likert-type scale ranging from 1 (not like me) to 5 (very much like me). Alpha levels for Waves 3 and 5 were .83 and .85 (strangers) and .89 and .90 (friends), respectively, indicating good internal consistency. Survey questions pertaining to PSB can be found in Appendix C. Separate scores were calculated by averaging the items for each subscale at both waves. The subscales of strangers and friends were both positively intercorrelated at both waves, with the correlation at Wave 3 being .60 and Wave 5 being .58 . Thus, due to the study not focusing on the differences between strangers or friends, both subscales were averaged together, and the average was used for the analyses. High scores correspond to high levels of PSB.

Anxiety. The generalized anxiety disorder subscale from the Spence Child Anxiety Inventory (Spence, 1998) was used to measure anxious behavior in adolescents at Waves 3 and 5. For this study, teens reported the frequency of feelings with higher scores reflecting greater levels of anxiety (e.g., "I worry that bad things will happen to me" and "When I have a problem, my heart beats really fast"). Teens answered six items on a four-point Likert-type scale ranging from 0 (never) to 3 (always). For Waves 3 and 5, Cronbach's $\alpha$ were .82 and .83, respectively and met the appropriate acceptable cutoff. Survey questions pertaining to anxiety can be found in Appendix D. Survey responses were averaged to create a single score in which high scores were 


\section{DOES HOPE MODERATE THE EFFECTS OF FINANCIAL DISTRESS}

an indicator of high levels of anxiety.

Control variables. Control variables included sex, race, age, and SES. Parents reported on their child's sex, race/ethnicity, and age via a questionnaire at Wave 1. Sex was originally coded such that $1=$ male and $2=$ female but was dummy coded for analyses as $0=$ male and $1=$ female. Race/ethnicity was originally coded such that $1=$ European American, $2=$ African American, 3 = Hispanic, $4=$ Asian American, $5=$ Other, $6=$ Multi-Ethnic. For analyses, race/ethnicity was represented as two dummy codes, with one representing Black race/ethnicity, such that $1=$ African American $=1$ and $0=$ other (not African American), and the second representing other minority race/ethnicity such that $1=$ other minority race/ethnicities, and $0=$ other. Age was measured based on the parents' response about their child's age in years. SES was gathered in Wave 3 through parents responding together (if able) about their annual income which was coded such that $1=$ Under $\$ 20,000$ per year, $2=$ At least $\$ 20,000$ per year, $3=A t$ least $\$ 30,000$ per year, $4=$ At least $\$ 40,000$ per year, $5=$ At least $\$ 50,000$ per year, $6=$ At least $\$ 60,000$ per year, $7=$ At least $\$ 70,000$ per year, $8=$ At least $\$ 80,000$ per year, $9=$ At least $\$ 90,000,10=$ At least $\$ 100,000$ per year, $11=$ At least $\$ 120,000$ per year, $12=\$ 150,000$ or more per year.

\section{Analysis Plan}

Preliminary analyses included descriptive statistics and bivariate correlations for FD, hope, PSB, anxiety, and the control variables (i.e., race/ethnicity, age, sex/gender, and SES). This included the total sample $N$, range, $M$, and $S D$, and bivariate correlations. Following these preliminary analyses, the hypotheses were tested using two series of linear regressions with four steps each to predict the two dependent variables, PSB and anxiety. Within these regressions, the first step examined the variance accounted for by the control variables (i.e., sex, race, age, and 
DOES HOPE MODERATE THE EFFECTS OF FINANCIAL DISTRESS

SES). In the second step, FD and hope were regressed upon the dependent variable. At the third step, the interaction between FD and hope was added in order to test the hypothesis about moderation. Interaction terms were calculated by using mean-centered variables, and significant interactions were explored via simple slopes tests. The fourth and last step examined how any significant associations may change with controlling for prior levels of each respective dependent variable at Wave 3. Analyses were run via SPSS. 
DOES HOPE MODERATE THE EFFECTS OF FINANCIAL DISTRESS

\section{Chapter IV}

\section{Results}

\section{Preliminary Analyses}

Table 1 shows the frequency of each variable by noting the mean, standard deviation, and range. Table 2 shows the correlations between each variable. Regarding the independent/control variables, analyses showed that FD was positively correlated with African American race. Therefore, African American adolescents reported higher levels of FD than other race/ethnic groups. In a similar vein, FD had a strong negative relationship with SES, meaning that adolescents who were in low SES families reported higher levels of FD than adolescents in high SES families. Analyses showed that there was also a strong negative relationship between African American race and hope, such that African American adolescents were significantly more likely to show high levels of hope than their peers. Hope was also correlated with age in that older adolescents displayed significantly higher levels of hope than their younger peers.

Table 1

Descriptive Statistics

\begin{tabular}{llll}
\hline Variable & $N$ & $M(S D) / \%$ & Range \\
\hline Male Sex & 478 & $46 \%$ & \\
African American & 483 & $12.4 \%$ & \\
All Other Ethnicities & 459 & $29.4 \%$ & $11.00-16.00$ \\
Child Age & 459 & $13.32(1.05)$ & $1.00-12.00$ \\
Parent Income (SES) & 354 & $8.17(3.14)$ & $1.00-4.91$ \\
FD W3 & 460 & $2.36(.84)$ & $1.00-4.60$ \\
Hope W3 & 459 & $2.28(.65)$ & $1.50-4.94$ \\
PSB W3 & 459 & $3.68(.62)$ & $1.89-5.00$ \\
PSB W5 & 465 & $3.81(.58)$ & $0.00-3.00$ \\
Anxiety W3 & 459 & $.89(.59)$ & $0.00-3.00$ \\
Anxiety W5 & 465 & $.97(.59)$ & \\
\hline
\end{tabular}

Note. $\mathrm{FD}=$ financial distress; $\mathrm{PSB}=$ prosocial behavior; $\mathrm{W}=$ wave. Hope was reverse scored. 
DOES HOPE MODERATE THE EFFECTS OF FINANCIAL DISTRESS

Table 2

Bivariate Correlations

\begin{tabular}{|c|c|c|c|c|c|c|}
\hline Variable & 1 & 2 & 3 & 4 & 5 & 6 \\
\hline \multicolumn{7}{|l|}{ 1. Sex } \\
\hline 2. African American & -.01 & & & & & \\
\hline 3. All Other Ethnicities & -.01 & $-.18 * *$ & & & & \\
\hline 4. Child Age & .04 & .06 & -.03 & & & \\
\hline 5. SES & .03 & $-.23 * *$ & -.07 & -.04 & & \\
\hline 6. FD W3 & -.01 & $.26 * *$ & -.05 & $.11 *$ & $-.56 * *$ & \\
\hline 7. Hope W3 & .06 & $-.14 * *$ & .03 & $.11^{*}$ & .01 & .00 \\
\hline 8. PSB W3 & $-.29 * *$ & $-.10^{*}$ & -.07 & $-.10 *$ & .03 & $-.09 *$ \\
\hline 9. PSB W5 & $-.28 * *$ & $-.18 * *$ & -.06 & -.04 & .00 & -.05 \\
\hline 10. Anxiety W3 & $-.18 * *$ & .06 & -.01 & .06 & $-.11 *$ & $.14 * *$ \\
\hline 11. Anxiety W5 & $-.24 * *$ & -.03 & .01 & .00 & .00 & .08 \\
\hline
\end{tabular}

Note. $\mathrm{FD}=$ financial distress; $\mathrm{PSB}=$ prosocial behavior; $\mathrm{W}=$ wave. Hope was reverse scored. ${ }^{*} p<.05$, $* * p<.01$.

\begin{tabular}{lcccc}
\hline Variable & \multicolumn{1}{c}{7} & 8 & 9 & 10 \\
\hline 1. & & & & \\
2. & & & & \\
3. & & & & \\
4. & & & & \\
5. & & & & \\
6. & & & & \\
7. & & & & \\
8. & $-.50^{* *}$ & & & \\
9. & $-.35^{* *}$ & $.66^{* *}$ & & \\
10. & .07 & $.12^{*}$ & $.14^{* *}$ & \\
11. & -.01 & $.18^{* *}$ & $.17^{* *}$ & $.53^{* *}$ \\
\hline
\end{tabular}

Correlational analyses also showed significant negative relationships at both waves between PSB and sex in addition to PSB and African American race. Therefore, girls were significantly more likely to exhibit high levels of PSB than were boys. Further, non-African American adolescents were significantly more likely to exhibit high levels of PSB than were African American adolescents. PSB at Wave 3 was also significantly correlated with FD at Wave 3, meaning that adolescents who were high in FD exhibited low prosociality; however, this 


\section{DOES HOPE MODERATE THE EFFECTS OF FINANCIAL DISTRESS}

association was not present at Wave 5. PSB at both waves was negatively correlated with hope: with the reverse-coding of hope in mind, adolescents who reported high levels of hope were significantly more likely also to show high levels of PSB.

Regarding anxiety, analyses showed a significant negative relationship with sex at both waves. These results mean that girls were significantly more likely to report higher levels of anxiety than boys. Anxiety was also negatively correlated with SES and positively correlated with FD at Wave 3. This means that adolescents who were low SES were likely to report higher anxiety. Further, adolescents who were in families that reported high levels of FD were likely to report high levels of anxiety. However, both significant relationships disappeared at Wave 5. An interesting relationship is that both waves of PSB and anxiety were significantly positively correlated to each other in both waves meaning that adolescents who reported high levels of anxiety were also likely to report high levels of PSB.

\section{Hypothesis Testing}

Preliminary analyses revealed a considerable amount of missing data for SES (see Table 1). As regression employs listwise deletion of missing data, it was necessary to estimate the models without this variable, and these are reported below. The second set of regressions in which SES was included are provided in Appendix E. Overall, there were no significant differences between the two sets of regressions, despite the reduced sample size when SES was included.

PSB. A four-step regression analysis was conducted to examine the potential relationships among FD, hope, and PSB (see Table 3). The first model step included the control variables (i.e., sex, race, and age). This step accounted for a significant portion of the variance, $F(4,427)=14.47, p<.001, R^{2}=.12$. PSB had significant associations with both sex and 


\section{DOES HOPE MODERATE THE EFFECTS OF FINANCIAL DISTRESS}

African American race, such that girls and non-African American adolescents were significantly more likely to exhibit high levels of PSB. There were nonsignificant effects for all other ethnicities in addition to age. The second model step included FD and hope and accounted for a significant additional portion of the variance in $\mathrm{PSB}, \Delta F(2,425)=39.05, p<.001, \Delta R^{2}=.14$. In this step, PSB retained a significant negative relationship with sex and African American ethnicity such that even with the inclusion of FD to the regression, girls and non-African American adolescents were significantly more likely to exhibit high levels of PSB. Furthermore, FD was not associated with PSB. However, there was a negative association with the addition of hope, meaning that adolescents who reported high levels of hope were likely to report high levels of PSB. Relative to the first step, the addition of FD and hope did not mitigate any of the associations for the control variables. On the third model step, the interaction between FD and hope did not account for any significant additional portion of the variance, $\Delta F(1,424)=0.01, p$

$=.93, \Delta R^{2}<.01$. The associations with sex, African American race, and hope remained significant from the previous steps. On the fourth step, controlling for prior levels of PSB accounted for a significant additional portion of the variance, $\Delta F(1,423)=171.17, p<.001, \Delta R^{2}$ $=.21$. High levels of PSB at Wave 3 were associated with high levels of PSB at Wave 5. Further, while the effects of sex and African American race persisted into this step, the association between PSB and hope was reduced to non-significance, meaning that hope does have a significant relationship to PSB. However, the stability over time was stronger than the relationship to hope. 
DOES HOPE MODERATE THE EFFECTS OF FINANCIAL DISTRESS

Table 3

Multiple Regression Analysis on Prosocial Behavior Without SES

\begin{tabular}{lcccccc}
\hline & \multicolumn{3}{c}{1} & & & 2 \\
\hline Variable & $B$ & $S E B$ & $\beta$ & $B$ & $S E B$ & $\beta$ \\
\hline Sex & -.33 & .05 & $-.29 * * *$ & -.31 & .05 & $-.27^{* * *}$ \\
African American & -.35 & .08 & $-.20 * * *$ & -.44 & .08 & $-.25^{* * *}$ \\
All Other Ethnicities & -.12 & .07 & -.08 & -.12 & .07 & -.08 \\
Child Age & -.01 & .03 & -.01 & .01 & .02 & .03 \\
FD W3 & & & & .01 & .03 & .02 \\
Hope W3 & & & -.34 & .04 & $-.38^{* * *}$ \\
Interaction & & & & & \\
PSB W3 & & & & & & \\
\hline$\Delta R^{2}$ & & & & & & \\
\hline
\end{tabular}

Note. $\mathrm{FD}=$ financial distress; $\mathrm{PSB}=$ prosocial behavior; $\mathrm{W}=$ wave. Hope was reverse scored. * $p<.05, * * p<.01, * * * p<.001$.

\begin{tabular}{cccccc}
\hline & 3 & & \multicolumn{3}{c}{4} \\
\hline$B$ & $S E B$ & $\beta$ & $B$ & $S E B$ & $\beta$ \\
\hline-.31 & .05 & $-.27 * * *$ & -.13 & .04 & $-.11^{* *}$ \\
-.44 & .08 & $-.25 * * *$ & -.26 & .07 & $-.15 * * *$ \\
-.12 & .07 & -.08 & -.04 & .05 & -.03 \\
.01 & .02 & .03 & .02 & .02 & .04 \\
.01 & .03 & .02 & .03 & .03 & .05 \\
-.34 & .04 & $-.38^{* * *}$ & -.07 & .04 & -.08 \\
.00 & .04 & .00 & -.05 & .04 & -.05 \\
& & & .55 & .04 & $.58^{* * *}$ \\
\hline
\end{tabular}

Anxiety. A four-step regression analysis was conducted to examine the potential relationships among FD, hope, and anxiety (see Table 4). The first model step included the control variables (i.e., sex, race, and age). This step accounted for a significant portion of the variance, $F(4,427)=6.54, p<.001, R^{2}=.06$. Anxiety had a significant negative association with sex, such that girls were more likely to report higher anxiety than boys. There were no significant associations between anxiety with race/ethnicity and age. The second model step included FD and hope, and this model step did not explain additional variance in anxiety, $\Delta F(2$, 
DOES HOPE MODERATE THE EFFECTS OF FINANCIAL DISTRESS

$425)=1.60, p=.20, \Delta R^{2}=.01$. In this step, anxiety retained a significant relationship with sex and nonsignificant relationships with all other control variables. On the third step, the interaction between FD and hope did not account for any significant change of the variance in anxiety, $\Delta F(1,424)=0.02, p=.89, \Delta R^{2}<.01$. The association between anxiety and sex remained significant, while all other nonsignificant relationships persisted. On the fourth step, controlling for prior levels of anxiety accounted for a significant portion of the variance, $\Delta F(1,423)=$ 155.50, $p<.001, \Delta R^{2}=.25$. Therefore, these results show that adolescent anxiety at Wave 3 was associated with anxiety at Waves 5 . In addition, the relationship between anxiety and sex became slightly weaker, while all other nonsignificant relationships remained.

Table 4

Multiple Regression Analysis on Anxiety Without SES

\begin{tabular}{lcccccc}
\hline & \multicolumn{3}{c}{1} & & & 2 \\
\hline Variable & $B$ & $S E B$ & $\beta$ & $B$ & $S E B$ & $\beta$ \\
\hline Sex & -.29 & .06 & $-.24 * * *$ & -.29 & .36 & $-.24^{* * *}$ \\
African American & -.04 & .09 & -.02 & -.08 & .06 & -.04 \\
All Other Ethnicities & .00 & .08 & .00 & .00 & .09 & .00 \\
Child Age & .01 & .03 & .02 & .01 & .07 & .01 \\
FD W3 & & & .06 & .03 & .09 \\
Hope W3 & & & .00 & .04 & .00 \\
Interaction & & & & & \\
Anxiety W3 & & & & & \\
\hline$\Delta R^{2}$ & & & & & & \\
\hline
\end{tabular}

Note. $\mathrm{FD}=$ financial distress; $\mathrm{PSB}=$ prosocial behavior; $\mathrm{W}=$ wave. Hope was reverse scored. * $p<.05, * * p<.01, * * * p<.001$. 
DOES HOPE MODERATE THE EFFECTS OF FINANCIAL DISTRESS

\begin{tabular}{cccccc}
\hline \multicolumn{3}{c}{3} & & \multicolumn{3}{c}{4} \\
\hline$B$ & $S E B$ & $\beta$ & $B$ & $S E B$ & $\beta$ \\
\hline-.29 & .06 & $-.24 * * *$ & -.17 & .05 & $-.14^{* *}$ \\
-.08 & .09 & -.04 & -.11 & .07 & -.06 \\
.00 & .08 & .00 & -.01 & .06 & -.01 \\
.01 & .03 & .01 & -.01 & .02 & -.02 \\
.06 & .04 & .09 & .01 & .03 & .02 \\
.00 & .05 & .00 & -.03 & .04 & -.03 \\
.01 & .05 & .01 & -.04 & .04 & -.04 \\
& & & .52 & .04 & $.52^{* * *}$ \\
\hline
\end{tabular}


DOES HOPE MODERATE THE EFFECTS OF FINANCIAL DISTRESS

\section{Chapter V}

\section{Discussion}

Adolescence is a critical period of development that can establish a myriad of positive and negative outcomes (Padilla-Walker et al., 2011). These outcomes may be hindered or promoted through various influences, such as FD. Previous studies have shown the sensitivity that adolescent development has for FD (McLoyd et al., 2009). However, relatively few studies have explored the potential promotive factors that may mitigate the harmful effects of FD. Therefore, this study's primary goal was to explore the moderating effect of an adolescent's hope on the associations between FD and PSB and anxiety.

Overall, the main goal of this study was to find out if there was a moderated relationship between FD and the outcomes via hope. Results show that hope failed to mitigate the effects of FD on PSB or anxiety over two years. This conflicts with the hypothesis that there would be a moderated relationship. This hypothesis was made based on scant literature in that no known studies previously considered the moderating role of hope on outcomes related to FD in adolescence. These results showed that for this study's outcomes of PSB and anxiety, FD did not have an effect, and hope did not moderate the relationship with FD. The null result of this study primarily supports two interpretations. First, hope is not a moderating factor for this combination of risk factor and outcomes at this point in development. Secondly, FD did not cause enough harm in this sample for hope to reveal whether it may act as a moderator. These two primary interpretations provide the perspective for this study's conclusions and future directions.

One reason for the lack of moderated effects is that the IV was not associated with the study outcomes (i.e., there was no longitudinal main effect of FD for hope to moderate). The study predicted a direct relationship between FD and PSB and anxiety. However, for both 


\section{DOES HOPE MODERATE THE EFFECTS OF FINANCIAL DISTRESS}

outcomes, correlational analyses showed that FD was associated with PSB and anxiety at Wave 3, but it did not persist longitudinally. Also, regression analyses show that FD at Wave 3 had no association with either outcome at Wave 5. One possible explanation for the lack of effects from FD over time may be due to a change in the families' levels of FD. The study waves used were between 2009 and 2011. Economic data from the U.S. Treasury Department (2012) show that, on average, household wealth increased over that time. Therefore, FD may have had a weaker and nonsignificant relationship in later waves due to the societal level change in economic resources, although the present analyses cannot ascertain whether these FFP study families experienced such gains.

With insight into FD in mind for PSB, no known literature explicitly linked FD and PSB in adolescence. However, in a sample of younger children, one study did find high levels of FD to be related to low levels of PSB (Chernyak et al., 2018). A similar relationship was expected for adolescence, yet none was found. Nevertheless, this study's bivariate correlations showed a relationship between FD and PSB within Wave 3, which dissipated at Wave 5. No longitudinal association may mean that by the time of adolescence, the effect of FD on PSB may give way to other external factors like parental influences (Ma, Shek, Cheung, \& Oi Bun Lam, 2000), peer groups (Hoorn, Dijk, Meuwese, Rieffe, \& Crone, 2016), or moral conviction and empathetic concern (Davis \& Carlo, 2020).

Regarding the relationship between FD and anxiety, as for PSB, FD was related to anxiety within Wave 3 but did not persist longitudinally nor account for any significant variance within the regression model. These results differ from prior studies. For example, one study in an all-female sample showed FD to be related to adolescent girls' internalizing behaviors (Lehman \& Koerner, 2002). Thus, a possible explanation as to why there was no association in between 


\section{DOES HOPE MODERATE THE EFFECTS OF FINANCIAL DISTRESS}

FD and either outcome in Wave 5 or in the regression analyses might be due to sex. A strong association between sex and adolescent anxiety is supported by prior research (e.g., Ohannessian et al., 2017). Therefore, it is possible that gender may moderate the association between FD and PSB and anxiety.

Another goal of this study was to understand the direct relationship between hope and the outcomes. Regarding the outcome of PSB, results show that hope had a correlational association with PSB across both waves. Further, hope explained a significant portion of the variance for PSB over time. Previous literature supports the conclusion of a link between hope and PSB (Padilla-Walker et al., 2011; Xiang, Cao, Yin, \& Liu, 2016). However, previous studies are cross-sectional, which limits longitudinal interpretation. When prior PSB was controlled for in this study, the influence hope had on PSB at Wave 5 was mitigated to non-significance. This result shows that although hope does have an independent influence on PSB, the more accurate representation of the data is that adolescents who were highly prosocial were likely to stay prosocial regardless of their degree of hope. This is consistent with prior studies (Eisenberg et al., 1999). Therefore, this study may provide insight for future studies regarding PSB. This study showed that PSB was consistent across waves. Therefore, future interpretations of results using PSB as an outcome should consider how stability plays a factor. Thus, because of high stability, there was limited variance for hope to explain.

Unlike PSB, hope did not have any correlational relationship with anxiety, nor did it account for significant variance in anxiety in the regression. Instead, the same narrative is applicable in that the stability of anxiety over time in adolescence is a more substantial influence than is hope. DiPierro et al. (2018) found a significant cross-sectional relationship such that low levels of hope were related to high levels of anxiety in Latino adolescents. Furthermore, through 


\section{DOES HOPE MODERATE THE EFFECTS OF FINANCIAL DISTRESS}

their study of college students, Arnau et al. (2007) showed that high hope had a longitudinal association with low anxiety. Their results imply that hope has the potential to be a resiliency factor. Although FD was not utilized as a risk factor, their results were taken in conjunction with prior research to hypothesize a similar pattern in this study. Nevertheless, the aforementioned cross-sectional and longitudinal studies have found a relationship that this study failed to support. A potential explanation for this difference may be that although there are studies that show a significant relationship between hope and anxiety (Yeung et al., 2015), there is simply no association between hope and anxiety in this sample at this point in development. For example, the cross-sectional study by DiPierro et al. (2018) used a convenience sample of 134 Latino adolescents $\left(M_{\text {age }}=16.14\right.$ years $)$ from a charter school, which is on average three years older than this study's sample. Additionally, the longitudinal study by Arnau et al. (2007) used a convenience sample of 522 undergraduate college students $\left(M_{\mathrm{age}}=18.70\right.$ years $)$, which was five years older than this study's sample. Although both studies show supporting results for this study's hypothesis, both samples are somewhat older than FFP youth were at Waves 3-5. Therefore, the different aged samples may account for the lack of concurrent results implying that there may not be an association between hope and anxiety in early adolescence but appear later in adolescence. Thus, future directions include replicating this effect in different samples of teens, as well as considering whether age may moderate this association.

This study also sought further to understand the direct connection between FD and hope. To date, no known study has explored the direct relationship between FD and hope as IVs. One study that examined FD and hope together in a population of adults (i.e., Prawitz et al., 2013) utilized them both as outcomes regarding how they were affected by mediating variables like a family's financial education and locus of control. They reported an interesting significant and 


\section{DOES HOPE MODERATE THE EFFECTS OF FINANCIAL DISTRESS}

positive correlation between them. In other words, they found that families who reported high levels of FD were also likely to report high levels of hope. Their sample was of adults instead of adolescents which raises questions of how this association may show up in different points of development. However, for this study's focus on adolescents, there was no association. These null results may induce doubt about FD or hope's influence on adolescent resilience, but there may be other potential insights. The null results show that FD and hope are independent of another. Contrary to the theoretical argument provided initially, hope may not be necessary for adolescents to exhibit resiliency despite FD. In other words, the level of an adolescent's hope is not a prerequisite for resilience. Instead, it may be that hope is evidence of a resilient process. Furthermore, understanding this independent relationship provides significant insight into adolescent resiliency in that teens can be hopeful even with high levels of FD. Adolescents during this time may not be knowledgeable about the details surrounding their family's FD by that point in development. Instead, resiliency may be shaped by other protective/promotive factors, such as supportive parenting, perceived community support, or high levels of enculturation (LaFromboise, Hoyt, Oliver, \& Whitbeck, 2006), while hope may be a beneficial buffer for other outcomes, such as defensive aggression (Halevy, 2017).

Lastly, concerning demographic control variables, this study supported the previous literature in that girls, non-African Americans, and older adolescents tended to show higher levels of PSB (Fabes et al., 1999; Padilla-Walker et al., 2018; Voight et al., 2014). However, these results showed that SES did not have a significant relationship with PSB, which is contradictory to previous literature, albeit the sample was comprised of 645 Portuguese adolescents (Simões et al., 2018). In other words, in this sample there was no connection between SES and PSB as opposed to findings in other samples. However, Simões et al. (2018) 


\section{DOES HOPE MODERATE THE EFFECTS OF FINANCIAL DISTRESS}

used a categorical SES measure that captured parental occupation status instead of income.

Differences in measuring SES may limit interpretations around possible associations and raise questions as to which dimensions of SES are related to a child's level of PSB.

Regarding the analysis of anxiety, previous literature has shown that girls, non-African American minority adolescents, early adolescents, and low SES adolescents tend to show significantly high levels of anxiety (Copeland et al., 2014; Gordon-Hollingsworth et al., 2015;

Ohannessian et al., 2017; Okamura et al., 2016; Sancakğlu et al., 2012). This study supports these premises for sex, age, race/ethnicity, and SES. However, this study found no differences in anxiety and race/ethnicity, while one study in particular (i.e., Okamura et al. 2016) showed that the minority adolescent subgroups of Chinese American, Filipino American, Japanese American, and Native American were all significantly more anxious than were Caucasian adolescents, which indicates some inconsistency in the literature around the relationship between anxiety and race/ethnicity. The data showed a significant relationship between anxiety and SES at Wave 3, but that relationship disappeared at Wave 5. One possible explanation is like the above proposition regarding the general sociocultural climate. FD and SES are significantly correlated (Reyes \& Yujuico, 2014), and if families during that time were becoming less financially distressed, it is possible their degree of SES may have also changed, thus eliminating the effect in the later wave. The results of this study and its differences with other studies may be a result of different populations and a shifting societal context.

\section{Strengths, Limitations \& Future Directions}

The present study was augmented by several strengths. First, one strength is the use of longitudinal design. In general, longitudinal designs help to reveal potential patterns over time. Therefore, the use of this longitudinal design could discover whether there were associations 


\section{DOES HOPE MODERATE THE EFFECTS OF FINANCIAL DISTRESS}

between FD, hope, PSB, and anxiety over time. Secondly, this study also had a large sample size of 500 adolescents, which is a strength for multiple reasons. For one, the large population allows for greater statistical power in the more consistent and reliable analyses. Secondly, the large sample size also allows for generalizable results. A third strength of the study is via the use of reliable measures, all of which have been validated and used in prior studies. Each interval-based measure had a high level of internal consistency allowing for reliable conclusions. A fourth major strength of the study was in asking a relatively novel question. As noted previously, the separate areas of literature addressing the effects and relationships between financial distress and hope in adolescence was scant. Therefore, answering a novel question grounded in an established theory (e.g., resilience theory) allows for further insight into the potential strengths and weaknesses of the given theory in addition to the overall literature.

As is true of all investigations, this study is not without its limitations. One is that, on average, the parents of the FFP sample reported low levels of FD. Therefore, the sample was relatively low risk, and this can create obstacles for analyzing relationships between risk factors and outcomes. Regarding the sample, future research should study FD in higher risk samples of youth who experience higher FD. This may produce different results than those reported here because FD has been shown to impact adolescent adjustment through other outcomes. For example, FD has been associated with other positive adjustment outcomes like educational achievement (Leung \& Shek, 2011), which has been shown to have an association with PSB (Caprara, Barbaranelli, Pastorelli, Bandura, \& Zimbardo, 2000). Further, FD has been associated with other adverse adjustment outcomes like delinquency (McLoyd et al., 2009), which is associated with anxiety (Mercer, Crocetti, Meeus, \& Branje, 2017). 


\section{DOES HOPE MODERATE THE EFFECTS OF FINANCIAL DISTRESS}

Additionally, the selected design may also have hindered the study. First, the study's longitudinal range may have played a role in the null effects. As mentioned earlier, FD lacked significance, which may have been due to the length of time between waves. It may be that FD has relatively short-term effects that do not persist across two years. Thus, if the study was over a single year, this may provide insight into FD as a risk factor by condensing the period better to accommodate the short-term effects of FD. Secondly, the study may benefit from a direct report of FD from the adolescent for this data may fill in the gaps in case an adolescent was not aware of their family's financial situation. Previous literature suggests that adolescents are most likely aware of FD via a study in which adolescents in less financially distressed families report healthier family functioning (Georgiades et al., 2008). However, an adolescent report, in conjunction with parental reports on FD, may matter for anxiety. Adolescents may become anxious if they are explicitly aware of their financial situation instead of being unaware of their family's resources and, therefore, not anxious about them which has been suggested through a study of adults (Dijkstra-Kersten et al., 2015). Thirdly, the study's measure for PSB does not include prosocial behaviors toward family members, as is the case in other studies involving PSB in adolescence (Mesurado \& Richaud, 2017; Padilla-Walker, Dyer, Yorgason, Fraser, \& Coyne, 2015). Prior FFP waves used a PSB measure that included family interactions but dropped that measure before the waves used for this study. Nevertheless, the inclusion of familial interactions is important because of its potential association with FD. FD was noted previously as impacting adolescent adjustment through parent-child interaction and overall family functioning (Georgiades et al., 2008; Prawitz et al., 2013). Therefore, a measure that does not include the prosocial interactions within the family may fail to capture the real influence of FD on that family. Lastly, the study's measure of anxiety does not allow for a diagnostic cutoff, which does 


\section{DOES HOPE MODERATE THE EFFECTS OF FINANCIAL DISTRESS}

distance this study from other adolescent literature (Gordon-Hollingsworth et al., 2015). To make it more consistent and in line with other studies on anxiety in adolescence, future studies should strongly consider using a clinical measure of anxiety that would distinguish between clinical and nonclinical levels of anxiety (e.g., Screen for Child Anxiety Related Emotional Disorders, Parent \& Child Forms [SCARED-C/P]; Birmaher, Khetarpal, Brent, Cully, Balach, Kaufman, \& Neer, 1997). The present sample reported low levels of anxiety, implying they were well adjusted. Thus, it may be that FD is indicative of clinically-significant levels of anxiety but not for levels below diagnostic thresholds.

An additional limitation may be regarding the ages of the adolescents during the study waves. This study supports prior literature in finding the same stability in other analyses of the FFP data (Coyne et al., 2012; Padilla-Walker et al., 2018). The stability between waves for PSB and anxiety may indicate that for this sample, these processes have already developmentally established themselves. In other words, PSB and anxiety may have shown stability because they were already stable by that point. This leaves questions about at what point before adolescence may the stability be insignificant and therefore leave the child's outcomes vulnerable to FD or hope. There are multiple instances stated earlier in which the reason why findings from this paper fail to support the findings of previous literature may be due to the period of development that these processes examined. Therefore, a future study should consider examining these relationships earlier in development (i.e., in pre-adolescence) or potentially later in adolescence and into emerging adulthood, which would be consistent with much of the previous literature cited in this study. For example, one study around the development of hope found a negative association between the initial state of hope and its subsequent growth. In particular, adolescents at a mean age of 14.3 years who began low in hope tended to increase their hope over time while 


\section{DOES HOPE MODERATE THE EFFECTS OF FINANCIAL DISTRESS}

those who started high in hope tended to decrease over time (Phan, 2013). The longitudinal change in the development of hope in addition to the awareness of FD implies that their interaction may be dependent on the period of development. Exploring these interactions may provide further insight as to how hope, or lack thereof, may influence the development of these outcomes despite FD.

This study also provides insight as to future directions in this line of research. For future studies interested in understanding how FD can affect adolescent development, other potential moderators should be considered. One possibility is social cohesion, as it buffers the effects that FD has on psychological distress (Erdem et al., 2016). Social cohesion is also comparable to many other promotive factors mentioned in resilience literature like peer support or parent-child relationships (Kumpfer, 2002; Masten, 2001). Thus, if hope does not moderate FD, contrary to original predictions, social cohesion would be a worthwhile moderator to examine to better understand adolescent FD. Furthermore, other studies have shown how PSB and anxiety have been moderated by other promotive factors like peer group status (Ellis \& Zarbatany, 2007) and parental autonomy granting (Verhoeven, Bögels, \& van der Bruggen, 2012), respectively, albeit both studies had different risk factors than FD. Nevertheless, this study sought to uncover the relationships among a novel combination of some relatively understudied factors (i.e., FD and hope) and produced null results. Therefore, any prior literature that shows some support for any of these associations tested in this study should consider expanding their parameters to include some of the variables in this study. Doing so may produce results that are important for future interventions.

An additional future direction would be to examine these processes using different outcome variables. For example, aggression is a widely studied outcome in adolescent research. 


\section{DOES HOPE MODERATE THE EFFECTS OF FINANCIAL DISTRESS}

However, there is little known literature addressing the potential impact FD may have on adolescent aggression, let alone how a moderator may alter said relationship. However, in a study using toddlers, financial strain was related to aggression (Stover et al., 2012) and a similar relationship may be expected to play out in adolescence. Regarding hope, there is little known literature explicitly examining the link between hope and aggression in adolescence. Therefore, there is ample room to explore these processes using aggression as an outcome. Furthermore, depression may also be an outcome that provides significant insight for future research. Although there is plenty of literature examining depression in adolescence, there is none found that uses FD as a predictor. Nevertheless, there is a clear relationship between FD and depression in adult populations (Jackson \& Warr, 1984) and a similar relationship is expected to play out in adolescence. Regarding hope, there is some evidence that shows high levels of hope to be related to lower levels of depression in adolescence (Du, King, \& Chu, 2016). However, the explicit relationship between $\mathrm{FD}$, hope, and depression has yet to be examined.

\section{Conclusions \& Implications}

Since adolescence is a sensitive period of development that has been historically viewed as a period of storm and stress (Steinberg \& Lerner, 2004), it is crucial for the field of developmental scholars to better understand the mechanisms that allow adolescents to be resilient despite the myriad of risk factors. Resiliency is an accessible process that every adolescent is capable of undergoing (Masten, 2001). This study provides significant insight into what adjustments are potentially needed in understanding resilience theory in adolescence. In particular, this study sought to answer whether hope could influence resiliency. However, results suggest that changes to resilience theory may be needed. For example, resilience theory may need to be more explicit as to the specificity of the risk and promotive factors in relation to the 


\section{DOES HOPE MODERATE THE EFFECTS OF FINANCIAL DISTRESS}

specific outcomes. For example, as previously mentioned, FD might have short term effects. Therefore, resilience theory may also need to be adjusted for time. It may need different models for different periods. More specifically, Van Breda (2018) described the need for distinguishing between durations of adversity (i.e., acute and chronic). Therefore, one model may be specific to a short-term process (e.g., one year) to better account for study frameworks like the proposed changes to this study. Another model may be long term (e.g., several decades or intergenerational) to better accommodate studies on historical trauma like the trauma faced by indigenous populations (Reinschmidt, Attakai, Kahn, Whitewater, \& Teufel-Shone, 2016). In sum, resilience theory may need models tailored to different lengths of time to account for the variety of short- and long-term processes.

Resilience theory may also require refinement to be more specific towards how adolescents experience risk at different points in development. One study has noted how not only does resilience look different for distinct communities but also at different ages (Bonanno \& Diminich, 2013). For example, the growth identity development during adolescence may influence various outcomes related to an adolescent's identity (Phan, 2013) which may then in turn effect outcomes like PSB or anxiety in addition to an adolescent's level of hope. Therefore, an adjusted resilience theory may capture the risk from FD differently in childhood or adulthood, rather than adolescence. However, it also may be entirely possible that FD is not a risk factor for adolescents as initially predicted.

For the outcomes, this study did show an association between hope and PSB but not anxiety. PSB, by nature, is relational. Hartling (2008) noted that resilience may not be within individuals or intrapsychic, but rather within social connections and relationships. This may mean that future studies' outcomes should be relational and observable like social competence. 


\section{DOES HOPE MODERATE THE EFFECTS OF FINANCIAL DISTRESS}

In a similar vein to the outcomes, resiliency theory may need refinement based on what promotive factors are influential to the process. This study found that hope was not a promotive factor for resiliency and it is unknown whether it may not be a factor in other contexts as well. Therefore, to better understand adolescent resilience, resilience theory needs to consider how adolescents interact with their environment explicitly. For example, Van Breda (2017) parsed out the resilience process as personal, interactional, or environmental (PIE). Based on that qualifier, this study's examination of an intrinsic and personal factor like hope, showed that in this sample at this point in development, it is not a moderator for an externally influenced risk factor like FD. This inconsistency in the risk factors and outcomes being both internal and external may provide insight into resilience theory revisions. For example, resilience theory may benefit from a consistent and explicit categorization of combinations of risk factors and outcomes that are appropriate to determine the resilient nature of a developmental process.

Lastly, this study provides insight into intervention and application efforts. Since the outcomes showed stability, it is advantageous for practitioners not to focus on FD or hope as the target point to promote positive development. Instead, this study shows via stability that practitioners should focus on PSB promotion or anxiety reduction directly and not through a moderated effect. Specifically, the focus should be on interventions like a multi-style approach for PSB that utilizes a helping plan, identifying their best self, figuring out their values, and doing daily prosocial behaviors (Baumsteiger, 2019). There is also the Anxiety Action Plan for anxiety (Ginsburg, Drake, Winegrad, Fothergill, \& Wissow, 2016) that utilizes cognitive behavioral therapy (CBT) through video demonstrations and role playing. Further, interventions may be useful if administered before roughly 13 years of age because this is the age when stability begins in the outcomes and persist over the next two years. Thus, the general idea is that 
DOES HOPE MODERATE THE EFFECTS OF FINANCIAL DISTRESS

if the respective outcomes can be promoted and reduced before early adolescence, these data suggest they should remain stable at their new levels after an intervention. 
DOES HOPE MODERATE THE EFFECTS OF FINANCIAL DISTRESS

\section{References}

Allen, S. F., Pfefferbaum, B., Nitiéma, P., Pfefferbaum, R. L., Houston, J. B., McCarter, G. S. I., \& Gray, S. R. (2016). Resilience and coping intervention with children and adolescents in at-risk neighborhoods. Journal of Loss and Trauma, 21, 85-98.

American Psychological Association. (2017). Ethical principles of psychologists and code of conduct. Washington, D.C.: Author. Accessed via https://www.apa.org/ethics/code/ethicscode-2017.pdf

Archuleta, K. L., Dale, A., \& Spann, S. M. (2013). College students and financial distress: Exploring debt, financial satisfaction, and financial anxiety. Journal of Financial Counseling and Planning, 24, 50-62.

Arnau, R. C. (2018). Hope and anxiety. In M. W. Gallagher \& S. J. Lopez (Eds.), The Oxford handbook of hope (pp. 221-231). Oxford: Oxford University Press.

Arnau, R. C., Rosen, D. H., Finch, J. F., Rhudy, J. L., \& Fortunato, V. J. (2007). Longitudinal effects of hope on depression and anxiety: A latent variable analysis. Journal of Personality, 75, 43-64.

Assari, S. (2018). Financial distress, anxiety, depression, and suicide among American college students. International Journal of Behavioral Sciences, 12, 84-90.

Barlow, D. H. (2000). Unraveling the mysteries of anxiety and its disorders from the perspective of emotion theory. American Psychologist, 55, 1247-1263.

Baumsteiger, R. (2019). What the world needs now: An intervention for promoting prosocial behavior. Basic and Applied Social Psychology, 41, 215-229.

Belfer, M. L. (2008). Child and adolescent mental disorders: The magnitude of the problem across the globe. Journal of Child Psychology and Psychiatry, 49, 226-236. 


\section{DOES HOPE MODERATE THE EFFECTS OF FINANCIAL DISTRESS}

Benson, M. J., Buehler, C., \& Gerard, J. M. (2008). Interparental hostility and early adolescent problem behavior: Spillover via maternal acceptance, harshness, inconsistency, and intrusiveness. The Journal of Early Adolescence, 28, 428-454.

Birmaher, B., Khetarpal, S., Brent, D., Cully, M., Balach, L., Kaufman, J., \& Neer, S. M. (1997). The screen for child anxiety related emotional disorders (SCARED): Scale construction and psychometric characteristics. Journal of the American Academy of Child \& Adolescent Psychiatry, 36, 545-553.

Bonanno, G. A., \& Diminich, E. D. (2013). Annual research review: Positive adjustment to adversity - trajectories of minimal-impact resilience and emergent resilience. Journal of Child Psychology and Psychiatry, 54, 378-401.

Bosquet, M., \& Egeland, B. (2006). The development and maintenance of anxiety symptoms from infancy through adolescence in a longitudinal sample. Development and Psychopathology, 18, 517-550.

Bryce, C. I., Alexander, B. L., Fraser, A. M., \& Fabes, R. A. (2020). Dimensions of hope in adolescence: Relations to academic functioning and well being. Psychology in the Schools, $57,171-190$.

Buckelew, S. P., Crittendon, R. S., Butkovic, J. D., Price, K. B., \& Hurst, M. (2008). Hope as a predictor of academic performance. Psychological Reports, 103, 411-414.

Callina, K. S., Johnson, S. K., Buckingham, M. H., \& Lerner, R. M. (2014). Hope in context: Developmental profiles of trust, hopeful future expectations, and civic engagement across adolescence. Journal of Youth and Adolescence, 43, 869-883.

Caprara, G. V., Barbaranelli, C., Pastorelli, C., Bandura, A., \& Zimbardo, P. G. (2000). Prosocial foundations of children's academic achievement. Psychological Science, 11, 302-306. 


\section{DOES HOPE MODERATE THE EFFECTS OF FINANCIAL DISTRESS}

Carlo, G., Padilla-Walker, L. M., \& Day, R. D. (2011). A test of the economic strain model on adolescents' prosocial behaviors. Journal of Research on Adolescence, 21, 842-848.

Chang, E., \& DeSimone, S. (2001). The influence of hope on appraisals, coping, and dysphoria: A test of hope theory. Journal of Social \& Clinical Psychology, 20, 117-129.

Chernyak, N., Harvey, T., Tarullo, A. R., Rockers, P. C., \& Blake, P. R. (2018). Varieties of young children's prosocial behavior in Zambia: The role of cognitive ability, wealth, and inequality beliefs. Frontiers in Psychology, 9, Article e2209.

Conger, R. D., Conger, K. J., \& Martin, M. J. (2010). Socioeconomic status, family processes, and individual development. Journal of Marriage and Family, 72, 685-704.

Conger, R. D., Elder, G. H., Lorenz, F. O., Simons, R. L., \& Whitbeck, L. B. (1992). A family process model of economic hardship and adjustment of early adolescent boys. Child Development, 63, 526-541.

Conger, R. D., Lorenz, F. O., Elder, G. H., Melby, J. N., Simons, R. L., \& Conger, K. J. (1991). A process model of family economic pressure and early adolescent alcohol use. The Journal of Early Adolescence, 11, 430-449.

Conger, R. D., Ge, X., Elder, G. H., Lorenz, F. O., \& Simons, R. L. (1994). Economic stress, coercive family process, and developmental problems of adolescents. Child Development, $65,541-561$

Copeland, W. E., Angold, A., Shanahan, L., \& Costello, E. J. (2014). Longitudinal patterns of anxiety from childhood to adulthood: The Great Smoky Mountains Study. Journal of the American Academy of Child and Adolescent Psychiatry, 53, 21-33.

Coyne, S. M., Stockdale, L., \& Summers, K. (2019). Problematic cell phone use, depression, anxiety, and self-regulation: Evidence from a three year longitudinal study from 
DOES HOPE MODERATE THE EFFECTS OF FINANCIAL DISTRESS

adolescence to emerging adulthood. Computers in Human Behavior, 96, 78-84.

Craske, M. G., Rauch, S. L., Ursano, R., Prenoveau, J., Pine, D. S., \& Zinbarg, R. E. (2009). What is an anxiety disorder? Depression \& Anxiety, 26, 1066-1085.

Davis, A. N., \& Carlo, G. (2020). Maternal warmth and prosocial behaviors among low-SES adolescents: Considering interactions between empathy and moral conviction. Journal of Moral Education, 49, 226-240.

Dijkstra-Kersten, S. M. A., Biesheuvel-Leliefeld, K. E. M., Wouden, J. C. van der, Penninx, B. W. J. H., \& Marwijk, H. W. J. van. (2015). Associations of financial strain and income with depressive and anxiety disorders. Journal of Epidemiology \& Community Health, 69, 660665.

DiPierro, M., Fite, P. J., \& Johnson-Motoyama, M. (2018). The role of religion and spirituality in the association between hope and anxiety in a sample of Latino youth. Child \& Youth Care Forum, 47, 101-114.

Du, H., King, R. B., \& Chu, S. K. W. (2016). Hope, social support, and depression among Hong Kong youth: Personal and relational self-esteem as mediators. Psychology, Health \& Medicine, 21, 926-931.

Eisenberg, N., Guthrie, I. K., Murphy, B. C., Shepard, S. A., Cumberland, A., \& Carlo, G. (1999). Consistency and development of prosocial dispositions: A longitudinal study. Child Development, 70, 1360-1372.

Elder, G. H., Jr., \& Caspi, A. (1988). Economic stress in lives: Developmental perspectives. Journal of Social Issues, 44, 25-45.

Ellis, W. E., \& Zarbatany, L. (2007). Peer group status as a moderator of group influence on children's deviant, aggressive, and prosocial behavior. Child Development, 78, 1240-1254. 


\section{DOES HOPE MODERATE THE EFFECTS OF FINANCIAL DISTRESS}

Erdem, Ö., Van Lenthe, F. J., Prins, R. G., Voorham, T. A. J. J., \& Burdorf, A. (2016). Socioeconomic inequalities in psychological distress among urban adults: The moderating role of neighborhood social cohesion. PLoS ONE, 11, 1-15.

Fabes, R. A., Carlo, G., Kupanoff, K., \& Laible, D. (1999). Early adolescence and prosocial/moral behavior I: The role of individual processes. The Journal of Early Adolescence, 19, 5-16.

Fergus, S., \& Zimmerman, M. A. (2005). Adolescent resilience: A framework for understanding healthy development in the face of risk. Annual Review of Public Health, 26, 399-419.

Fite, P. J., Gabrielli, J., Cooley, J. L., Haas, S. M., Frazer, A., ...Johnson-Motoyama, M. (2014). Hope as a moderator of the associations between common risk factors and frequency of substance use among Latino Adolescents. Journal of Psychopathology and Behavioral Assessment, 36, 653-662.

Frasquilho, D., de Matos, M., Marques, A., Neville, F., Gaspar, T., Caldas-de-Almeida, J., ...Caldas-de-Almeida, J. M. (2016). Unemployment, parental distress and youth emotional well-being: The moderation roles of parent-youth relationship and financial deprivation. Child Psychiatry \& Human Development, 47, 751-758.

Georgiades, K., Boyle, M. H., Jenkins, J. M., Sanford, M., \& Lipman, E. (2008). A multilevel analysis of whole family functioning using the McMaster Family Assessment Device. Journal of Family Psychology, 22, 344-354.

Glass, K., Flory, K., Hankin, B. L., Kloos, B., \& Turecki, G. (2009). Are coping strategies, social support, and hope associated with psychological distress among Hurricane Katrina survivors? Journal of Social and Clinical Psychology, 28, 779-795.

Ginsburg, G., Drake, K., Winegrad, H., Fothergill, K., \& Wissow, L. (2016). An open trial of the 
DOES HOPE MODERATE THE EFFECTS OF FINANCIAL DISTRESS

anxiety action plan (AxAP): A brief pediatrician-delivered intervention for anxious youth. Child \& Youth Care Forum, 45, 19-32.

Gordon-Hollingsworth, A., Becker, E., Ginsburg, G., Keeton, C., Compton, S., Birmaher, B., ...March, J. (2015). Anxiety disorders in Caucasian and African American children: A comparison of clinical characteristics, treatment process variables, and treatment outcomes. Child Psychiatry \& Human Development, 46, 643-655.

Grusec, J. E., Davidov, M., \& Lundell, L. (2002). Prosocial and helping behavior. In P. K. Smith \& C. H. Hart (Eds.), Blackwell handbook of childhood social development (pp. 457-474). Hoboken, NJ: Blackwell Publishing.

Halevy, N. (2017). Preemptive strikes: Fear, hope, and defensive aggression. Journal of Personality and Social Psychology, 112, 224-237.

Hartling, L. M. (2008). Strengthening resilience in a risky world: It's all about relationships. Women \& Therapy, 31, 51-70.

Hollingsworth, D. W., Wingate, L. R., Tucker, R. P., O'Keefe, V. M., \& Cole, A. B. (2016). Hope as a moderator of the relationship between interpersonal predictors of suicide and suicidal thinking in African Americans. Journal of Black Psychology, 42, 175-190.

Hoorn, J. van, Dijk, E. van, Meuwese, R., Rieffe, C., \& Crone, E. A. (2016). Peer influence on prosocial behavior in adolescence. Journal of Research on Adolescence, 26, 90-100.

Hope. (n.d.) In Dictionary.com's online dictionary. Retrieved from https://www.dictionary.com/browse/hope?s=t

Horton, T. V., \& Wallander, J. L. (2001). Hope and social support as resilience factors against psychological distress of mothers who care for children with chronic physical conditions. Rehabilitation Psychology, 46, 382-399. 


\section{DOES HOPE MODERATE THE EFFECTS OF FINANCIAL DISTRESS}

Jackson, P. R., \& Warr, P. B. (1984). Unemployment and psychological ill-health: The moderating role of duration and age. Psychological Medicine, 14, 605-614.

Jiang, Y., Ren, Y., Liang, Q., \& You, J. (2018). The moderating role of trait hope in the association between adolescent depressive symptoms and nonsuicidal self-injury. Personality and Individual Differences, 135, 137-142.

Knight, G. P., \& Kagan, S. (1977). Development of prosocial and competitive behaviors in Anglo-American and Mexican-American children. Child Development, 48, 1385-1394.

Kumpfer, K. L. (2002). Factors and processes contributing to resilience. In M. D. Glantz \& J. L. Johnson (Eds.), Resilience and development (pp. 179-224). Boston, MA: Springer.

LaFromboise, T. D., Hoyt, D. R., Oliver, L., \& Whitbeck, L. B. (2006). Family, community, and school influences on resilience among American Indian adolescents in the upper midwest. Journal of Community Psychology, 34, 193-209.

Lehman, S. J., \& Koerner, S. S. (2002). Family financial hardship and adolescent girls' adjustment: The role of maternal disclosure of financial concerns. Merrill-Palmer Quarterly, 48, 1-24.

Lempers, J. D., Clark-Lempers, D., \& Simons, R. L. (1989). Economic hardship, parenting, and distress in adolescence. Child Development, 60, 25-39.

Letcher, P., Sanson, A., Smart, D., \& Toumbourou, J. (2012). Precursors and correlates of anxiety trajectories from late childhood to late adolescence. Journal of Clinical Child \& Adolescent Psychology, 41, 417-432.

Leung, J. T., \& Shek, D. T. (2011). Poverty and adolescent developmental outcomes: A critical review. International Journal of Adolescent Medicine and Health, 23, 109-114.

Luthar, S. S., Cicchetti, D., \& Becker, B. (2000). The construct of resilience: A critical 
DOES HOPE MODERATE THE EFFECTS OF FINANCIAL DISTRESS

evaluation and guidelines for future work. Child Development, 71, 543-562.

Lee, C. T., Padilla-Walker, L. M., \& Memmott-Elison, M. K. (2017). The role of parents and peers on adolescents' prosocial behavior and substance use. Journal of Social and Personal Relationships, 34, 1053-1069.

Little, T. D., Snyder, R., \& Wehmeyer, M. L. (2006). The agentic self: On the nature and origins of personal agency across the lifespan. In D. Mroczek \& T. D. Little (Eds.), The handbook of personality development (pp. 61-79). Mahwah, NJ: Erlbaum.

Ma, H. K., Shek, D. T. L., Cheung, P. C., \& Oi Bun Lam, C. (2000). Parental, peer, and teacher influences on the social behavior of Hong Kong Chinese adolescents. Journal of Genetic Psychology, 161, 65-78.

Masten, A. S. (1994). Resilience in individual development: Successful adaptation despite risk and adversity: Challenges and prospects. In M. Wang \& E. Gordon (Eds.), Educational resilience in inner city America: Challenges and prospects (pp. 3-25). Mahwah, NJ: Erlbaum.

Masten, A. S. (2001). Ordinary magic: Resilience processes in development. American Psychologist, 56, 227-238.

McLoyd, V. C., Kaplan, R., Purtell, K. M., Bagley, E., Hardaway, C. R., \& Smalls, C. (2009). Poverty and socioeconomic disadvantage in adolescence. In R. M. Lerner \& L. Steinberg (Eds.), Handbook of adolescent psychology: Contextual influences on adolescent development (pp. 444-491). Hoboken, NJ: John Wiley \& Sons Inc.

Mesurado, B., \& Richaud, M. C. (2017). The relationship between parental variables, empathy and prosocial-flow with prosocial behavior toward strangers, friends, and family. Journal of Happiness Studies: An Interdisciplinary Forum on Subjective Well-Being, 18, 843-860. 


\section{DOES HOPE MODERATE THE EFFECTS OF FINANCIAL DISTRESS}

Michael, S. T. (2000). Hope conquers fear: Overcoming anxiety and panic attacks. In C. R. Snyder (Eds.), Handbook of hope (pp. 301-319). Cambridge, MA: Academic Press.

Mercer, N., Crocetti, E., Meeus, W., \& Branje, S. (2017). Examining the relation between adolescent social anxiety, adolescent delinquency (abstention), and emerging adulthood relationship quality. Anxiety, Stress, \& Coping, 30, 428-440.

Ng, E. C. W., Lam, J. K. M., \& Chan, C. C. H. (2017). The positive adjustment of low-income youths with relational and community support: The mediating role of hope. Merrill-Palmer Quarterly, 63, 514-542.

Nolan, C., \& Stitzlein, S. (2011). Meaningful hope for teachers in times of high anxiety and low morale. Democracy and Education, 19, Article e2.

Ohannessian, C. M., Cavanaugh, A., \& Cheeseman, K. (2017). Gender and racial/ethnic differences in anxiety disorders during adolescence. Adolescent Psychiatry, 12, 13-24.

Okamura, K., Ebesutani, C., Bloom, R., Higa-McMillan, C., Nakamura, B., \& Chorpita, B. (2016). Differences in internalizing symptoms across specific ethnic minority groups: An analysis across Chinese American, Filipino American, Japanese American, Native Hawaiian, and white youth. Journal of Child \& Family Studies, 25, 3353-3366.

Padilla-Walker, L. M., Carlo, G., \& Memmott-Elison, M. K. (2018). Longitudinal change in adolescents' prosocial behavior toward strangers, friends, and family. Journal of Research on Adolescence, 28, 698-710.

Padilla-Walker, L. M., Carlo, G., \& Nielson, M. G. (2015). Does helping keep teens protected? Longitudinal bidirectional relations between prosocial behavior and problem behavior. Child Development, 86, 1759-1772.

Padilla-Walker, L. M., Dyer, W. J., Yorgason, J. B., Fraser, A. M., \& Coyne, S. M. (2015). 
DOES HOPE MODERATE THE EFFECTS OF FINANCIAL DISTRESS

Adolescents' prosocial behavior toward family, friends, and strangers: A person-centered approach. Journal of Research on Adolescence, 25, 135-150.

Padilla-Walker, L. M., Hardy, S. A., \& Christensen, K. J. (2011). Adolescent hope as a mediator between parent-child connectedness and adolescent outcomes. The Journal of Early Adolescence, 31, 853-879.

Padilla-Walker, L. M., Harper, J. M., \& Bean, R. A. (2011). Pathways to parental knowledge: The role of family process and family structure. The Journal of Early Adolescence, 31, 604627.

Peterson, C., \& Seligman, M. E. P. (2004). Character strengths and virtues: A handbook and classification. Washington, DC: Oxford University Press.

Phan, H. P. (2013). Examination of self-efficacy and hope: A developmental approach using latent growth modeling. The Journal of Educational Research, 106, 93-104.

Prawitz, A. D., Kalkowski, J. C., \& Cohart, J. (2013). Responses to economic pressure by lowincome families: Financial distress and hopefulness. Journal of Family and Economic Issues, 34, 29-40.

Rand, K. L., \& Cheavens, J. S. (2009). Hope theory. In S. J. Lopez \& C. R. Snyder (Eds.), The Oxford handbook of positive psychology (pp. 323-343). Oxford, UK: Oxford University Press.

Reinschmidt, K. M., Attakai, A., Kahn, C. B., Whitewater, S., \& Teufel-Shone, N. (2016). Shaping a stories of resilience model from urban American Indian elders' narratives of historical trauma and resilience. American Indian \& Alaska Native Mental Health Research, $23,63-85$.

Russell, M. A., \& Odgers, C. L. (2020). Adolescents' subjective social status predicts day to day 
DOES HOPE MODERATE THE EFFECTS OF FINANCIAL DISTRESS

mental health and future substance use. Journal of Research on Adolescence, 30, 532-544.

Sancakğlu, S., \& Sayar, M. K. (2012). Relation between socioeconomic status and depression, anxiety, and self-esteem in early adolescents. Yeni Symposium: Psikiyatri, Nöroloji ve Davraniş Bilimleri Dergisi, 50, 207-220.

Schmid, K. L., Phelps, E., Kiely, M. K., Napolitano, C. M., Boyd, M. J., \& Lerner, R. M. (2011). The role of adolescents' hopeful futures in predicting positive and negative developmental trajectories: Findings from the 4-H study of positive youth development. The Journal of Positive Psychology, 6, 45-56.

Selenko, E., \& Batinic, B. (2011). Beyond debt. A moderator analysis of the relationship between perceived financial strain and mental health. Social Science \& Medicine, 73, 17251732.

Shek, D. T. L. (2004). Beliefs about causes of poverty and psychological well-being of parents and adolescents experiencing economic disadvantage in Hong Kong. The American Journal of Family Therapy, 32, 239-254.

Simões, F., Calheiros, M. M., \& Alarcão e Silva, M. M. (2018). Socioeconomic status, multiple autonomy support attunement, and early adolescents' social development. Journal of Community Psychology, 46, 790-805.

Snyder, C. R. (2002). Hope theory: Rainbows in the mind. Psychological Inquiry, 13, 249-275.

Snyder, C. R. (2006). Measuring hope in children. Adolescent \& Family Health, 4, 26-34.

Snyder, C. R., Cheavens, J., \& Sympson, S. C. (1997). Hope: An individual motive for social commerce. Group Dynamics: Theory, Research, and Practice, 1, 107-118.

Southwick, S. M., Bonanno, G. A., Masten, A. S., Panter-Brick, C., \& Yehuda, R. (2014). Resilience definitions, theory, and challenges: Interdisciplinary perspectives. European 
DOES HOPE MODERATE THE EFFECTS OF FINANCIAL DISTRESS

Journal of Psychotraumatology, 5, Article e25338.

Spence, S. H. (1998). A measure of anxiety symptoms among children. Behaviour Research and Therapy, 36, 545-566.

Spilman, S. K., \& Burzette, R. G. (2006). Critical Transitions Project Technical Reports, F10 2003. Ames, IA: Family Transitions Project, Iowa State University.

Staub, E. (1995). The roots of prosocial and antisocial behavior in persons and groups: Environmental influence, personality, culture, and socialization. In W. M. Kurtines \& J. L. Gewirtz (Eds.), Moral development: An introduction (pp. 431-453). Needham Heights, MA: Allyn \& Bacon.

Steinberg, L., \& Lerner, R. M. (2004). The scientific study of adolescence: A brief history. The Journal of Early Adolescence, 24, 45-54.

Stover, C. S., Connell, C. M., Leve, L. D., Neiderhiser, J. M., Shaw, D. S., Scaramella, L. V., ...Reiss, D. (2012). Fathering and mothering in the family system: Linking marital hostility and aggression in adopted toddlers. Journal of Child Psychology and Psychiatry, 53, 401409.

Thielmann, I., Spadaro, G., \& Balliet, D. (2020). Personality and prosocial behavior: A theoretical framework and meta-analysis. Psychological Bulletin, 146, 30-90.

U.S. Department of Treasury. (2012). Recent economic growth in charts [Infographic]. Treasury.gov. https://www.treasury.gov/resource-center/data-chartcenter/Documents/20120502_EconomicGrowth.pdf

Valle, M. F., Huebner, E. S., \& Suldo, S. M. (2004). Further evaluation of the children's hope scale. Journal of Psychoeducational Assessment, 22, 320- 337.

Valle, M. F., Huebner, E. S., \& Suldo, S. M. (2006). An analysis of hope as a psychological 
DOES HOPE MODERATE THE EFFECTS OF FINANCIAL DISTRESS

strength. Journal of School Psychology, 44, 393-406.

Van Breda, A. D. (2017). The youth ecological-resilience scale: A partial validation. Research on Social Work Practice, 27, 248-257.

Van Breda, A. D. (2018). A critical review of resilience theory and its relevance for social work. Social Work, 54, 1-18.

Verhoeven, M., Bögels, S. M., \& van der Bruggen, C. C. (2012). Unique roles of mothering and fathering in child anxiety; Moderation by child's age and gender. Journal of Child and Family Studies, 21, 331-343.

Voight, A. M., Geller, J. D., \& Nation, M. (2014). Contextualizing the "behavior gap": Student prosocial behavior and racial composition in urban middle schools. The Journal of Early Adolescence, 34, 157-177.

Weis, R., \& Speridakos, E. C. (2011). A meta-analysis of hope enhancement strategies in clinical and community settings. Psychology of Well-Being: Theory, Research and Practice, 1, 116.

Wentzel, K. R., Filisetti, L., \& Looney, L. (2007). Adolescent prosocial behavior: The role of self-processes and contextual cues. Child Development, 78, 895-910.

Wilkinson, R. G. (1999). Health, hierarchy, and social anxiety. Annals of the New York Academy of Sciences, 896, 48-63.

Xiang, B., Cao, J., Yin, X., \& Liu, J. (2016). Effects of divorced parents' emotional intelligence on children's emotional and behavior adjustment: The mediating role of children's hope. Chinese Journal of Clinical Psychology, 24, 943-945.

Yeung, D. Y., Ho, S. M. Y., \& Mak, C. W. Y. (2015). Brief report: Attention to positive information mediates the relationship between hope and psychosocial well-being of 
DOES HOPE MODERATE THE EFFECTS OF FINANCIAL DISTRESS

adolescents. Journal of Adolescence, 42, 98-102.

Yin, X., Li, Z., Yuan, Y., \& Wang, Z. (2019). Developmental trajectory of hope among lateadolescents: Population heterogeneity and the impact of gender and family socioeconomic status. Journal of Adolescence, 72, 124-131.

Zimmerman, M. A., Stoddard, S. A., Eisman, A. B., Caldwell, C. H., Aiyer, S. M., \& Miller, A. (2013). Adolescent resilience: Promotive factors that inform prevention. Child Development Perspectives, 7, 215-220. 
DOES HOPE MODERATE THE EFFECTS OF FINANCIAL DISTRESS

\section{Appendix A}

\section{Family Transitions Project:}

Stem: How much do you agree or disagree with each of the following statements about your financial situation?

Response Categories (Items 1-11): 1 (strongly disagree) to 5 (strongly agree)

Variable Name Variable Labels: Adult

p1finstress1__ I have trouble sleeping because of my financial problems.

p1finstress2__ I am concerned because I cannot afford adequate health insurance.

p1 finstress3_ I I often worry about my financial situation.

plfinstress4_ $\quad$ My financial situation is much worse this year than it was a year ago.

p1 finstress5_ I I not know how I will be able to support myself in the next year.

p1 finstress6__ I have enough money to afford the kind of place to live in that I should have.

p1finstress7_ $\quad$ I have enough money to afford the kind of clothing that I should have.

p1finstress8__ I have enough money to afford the kind of furniture or household appliances that I should have.

p1finstress9__ I have enough money to afford the kind of car that I need.

p1finstress10__ I have enough money to afford the kind of food that I need.

p1finstress11_ I have enough money to afford the kind of medical care that I need.

Response Categories (Item 12): 1 (no difficulty at all) to 5 (a great bit of difficulty)

p1finstress12__ During the past 12 months, how much difficulty have you had in paying your bills?

Response Categories (Item 13): 1 (not enough money to make ends meet) to 4 (more than enough money left over)

p1finstress13_ $\quad$ Over the past 12 months, at the end of each month, do you generally end up with... 
DOES HOPE MODERATE THE EFFECTS OF FINANCIAL DISTRESS

\section{Appendix B}

\section{Hope/Optimism Scale:}

\section{Stem (Waves II-VII): Is this statement like you?}

Response Categories (Waves II-V) (Items 1-10): 1 (very much like me) to 5 (very much unlike me)

$\begin{array}{ll}\text { Variable Name } & \text { Variable Labels } \\ \text { c_hope1_ } & \text { I always look on the bright side. } \\ \text { c_hope2_ } & \text { I can always find the positive in what seems negative to others. } \\ \text { c_hope3_ } & \text { Despite challenges, I always remain hopeful about the future. } \\ \text { c_hope4_ } & \begin{array}{l}\text { I have a clear picture in my mind about what I want to happen in the } \\ \text { future. }\end{array} \\ \text { c_hope5_ } & \begin{array}{l}\text { If I get a bad grade or evaluation, I focus on the next opportunity, and } \\ \text { plan to do better. }\end{array} \\ \text { c_hope6_ } & \text { I have a plan for what I want to be doing five years from now. } \\ \text { c_hope7_ } & \text { I know that I will succeed with the goals I set for myself. } \\ \text { c_hope8_ } & \text { I am confident that my way of doing things will work out for the best. } \\ \text { c_hope9_ } & \text { If I feel down, I always think about what is good in my life. } \\ \text { c_hope10 } & \text { I expect the best. }\end{array}$


DOES HOPE MODERATE THE EFFECTS OF FINANCIAL DISTRESS

\section{Appendix C}

\section{Inventory of Strengths:}

Response Categories (Items 1-18): 1 (Not like me at all) to 5 (Very much like me)

Variable Name $\quad$ Variable Labels: Child

c_prosoc1_ I help people I don't know, even if it is not easy for me.

c_prosoc2_ I really enjoy doing small favors for people I do not know.

c_prosoc3_ I I go out of my way to cheer up people who seem sad, even if I do not know them.

c_prosoc4_ I voluntarily help my neighbors.

c_prosoc5_ I help other kids at school (with things like homework, sports, or other activities).

c_prosoc6_ I volunteer in programs to help others in need (like food or clothing drives, service groups or other volunteer projects).

c_prosoc7_ I am involved in service at my school (such as student council or student government).

c_prosoc8_ I enjoy being kind to others, even if I do not know them

c_prosoc9_ I watch out for kids at school, even if I do not know them.

c_pbfriend1_ I help my friends, even if it is not easy for me.

c_pbfriend2_ I really enjoy doing small favors for my friends.

c_pbfriend3_ I I go out of my way to cheer up my friends when they seem sad.

c_pbfriend4__ I voluntarily help my friends.

c_pbfriend5__ I always listen to my friends talk about their problems.

c_pbfriend6__ I enjoy being kind to my friends.

c_pbfriend7_ I love to make my friends happy.

c_pbfriend8__ I tell my friends how much they mean to me.

c_pbfriend9_ I watch out for my friends. 
DOES HOPE MODERATE THE EFFECTS OF FINANCIAL DISTRESS

\section{Appendix D}

\section{Generalized Anxiety Disorder Subscale of the Spence Child Anxiety Inventory:}

Stem: How often do you experience the following?

Response Categories (Items 1-6): 0 (never) to 3 (always)

Variable Name Variable Labels

c_anx1_ I worry about things.

c_anx2_ When I have a problem, I get a funny feeling in my stomach.

c_anx3__ I feel afraid.

c_anx4__ When I have a problem, my heart beats really fast.

c_anx5_ I worry that something bad will happen to me.

c_anx6_ When I have a problem, I feel shaky. 
DOES HOPE MODERATE THE EFFECTS OF FINANCIAL DISTRESS

Table E1

Appendix E

Multiple Regression Analysis on Prosocial Behavior with SES

\begin{tabular}{|c|c|c|c|c|c|c|c|c|c|c|c|c|}
\hline & \multicolumn{3}{|c|}{1} & \multicolumn{3}{|c|}{2} & \multicolumn{3}{|c|}{3} & \multicolumn{3}{|c|}{4} \\
\hline Variable & $B$ & $S E B$ & $\beta$ & $B$ & $S E B$ & $\beta$ & $B$ & $S E B$ & $\beta$ & $B$ & $S E B$ & $\beta$ \\
\hline Sex & -.413 & .06 & $-.35 * * *$ & -.37 & .06 & $-.32 * * *$ & -.37 & .06 & $-.32 * * *$ & -.19 & .05 & $-.17 * * *$ \\
\hline African American & -.32 & .12 & $-.14 * *$ & -.43 & .11 & $-.19 * * *$ & -.43 & .11 & $-.19 * * *$ & -.28 & .10 & $-.13 * *$ \\
\hline All Other Ethnicities & -.13 & .08 & $-.09 *$ & -.11 & .07 & -.08 & -.11 & .07 & -.07 & -.05 & .06 & -.03 \\
\hline Child Age & .01 & .03 & .01 & .02 & .03 & .03 & .02 & .03 & .03 & .02 & .02 & .03 \\
\hline SES & .00 & .01 & -.02 & .00 & .01 & -.02 & .00 & .01 & -.02 & .00 & .01 & .00 \\
\hline FD W3 & & & & .01 & .04 & .01 & .01 & .04 & .01 & .02 & .04 & .03 \\
\hline Hope W3 & & & & -.36 & .05 & $-.36 * * *$ & -.35 & .05 & $-.36 * * *$ & $-.10^{*}$ & .05 & -.10 \\
\hline Interaction & & & & & & & .02 & .06 & .02 & -.04 & .05 & -.03 \\
\hline PSB W3 & & & & & & & & & & .52 & .05 & $.55 * * *$ \\
\hline$\Delta R^{2}$ & & & $.15^{*}$ & & & $.13^{*}$ & & & .00 & & & $.20 *$ \\
\hline
\end{tabular}

Note. $\mathrm{FD}=$ financial distress; $\mathrm{PSB}=$ prosocial behavior; $\mathrm{W}=$ Wave. Hope was reverse scored. $* p<.05, * * p<.01, * * * p<.001$. 
DOES HOPE MODERATE THE EFFECTS OF FINANCIAL DISTRESS

\section{Table E2}

Multiple Regression Analysis on Anxiety with SES

\begin{tabular}{|c|c|c|c|c|c|c|c|c|c|c|c|c|}
\hline & \multicolumn{3}{|c|}{1} & \multicolumn{3}{|c|}{2} & \multicolumn{3}{|c|}{3} & \multicolumn{3}{|c|}{4} \\
\hline Variable & $B$ & $S E B$ & $\beta$ & $B$ & $S E B$ & $\beta$ & $B$ & $S E B$ & $\beta$ & $B$ & $S E B$ & $\beta$ \\
\hline Sex & -.30 & .06 & -.25 & -.30 & .07 & $-.25 *$ & -.31 & .07 & $-.26 * * *$ & -.18 & .06 & $-.15 * *$ \\
\hline African American & -.02 & .13 & $-.01 * * *$ & -.02 & .13 & $-.01 * * *$ & -.02 & .13 & -.01 & -.13 & .11 & -.05 \\
\hline All Other Ethnicities & -.01 & .09 & .00 & .01 & .09 & .01 & .01 & .09 & .01 & -.04 & .07 & -.02 \\
\hline Child Age & -.02 & .03 & -04 & -.03 & .03 & -.04 & -.03 & .03 & -.04 & -.05 & .03 & -.08 \\
\hline SES & .00 & .01 & .00 & .01 & .01 & .06 & .01 & .01 & .05 & .01 & .01 & .05 \\
\hline FD W3 & & & & .08 & .05 & .10 & .08 & .05 & .11 & .01 & .04 & .02 \\
\hline Hope W3 & & & & .01 & .05 & .01 & .01 & .06 & .01 & -.02 & .05 & -.02 \\
\hline Interaction & & & & & & & .06 & .06 & .05 & -.01 & .05 & -.01 \\
\hline Anxiety W3 & & & & & & & & & & .57 & .05 & $.56 * * *$ \\
\hline$\Delta R^{2}$ & & & $.06 * *$ & & & .01 & & & .00 & & & $.25 * * *$ \\
\hline
\end{tabular}

Note. $\mathrm{FD}=$ financial distress; $\mathrm{PSB}=$ prosocial behavior; $\mathrm{W}=$ Wave. Hope was reverse scored. $* p<.05, * * p<.01, * * * p<.001$. 
DOES HOPE MODERATE THE EFFECTS OF FINANCIAL DISTRESS

Table F1

\section{Appendix F}

Multiple Regression Analysis on Prosocial Behavior without SES

\begin{tabular}{lccccccccc}
\hline & \multicolumn{3}{c}{1} & \multicolumn{3}{c}{2} & & \multicolumn{3}{c}{3} \\
\hline Variable & $B$ & $S E B$ & $\beta$ & $B$ & $S E B$ & $\beta$ & $B$ & $S E B$ & $\beta$ \\
Sex & -.34 & .06 & $-.27^{* * *}$ & -.31 & .05 & $-.25^{* * *}$ & -.32 & .05 & $-.26^{* * *}$ \\
African American & -.21 & .09 & $-.11^{* *}$ & -.31 & .08 & $-.17^{* * *}$ & -.31 & .08 & $-.18^{* * *}$ \\
All Other Ethnicities & -.15 & .08 & $-.09^{*}$ & -.15 & .06 & $-.09^{*}$ & -.15 & .06 & $-.09^{*}$ \\
Child Age & -.05 & .03 & -.08 & -.01 & .02 & -.02 & -.01 & .02 & -.02 \\
FD W3 & & & & -.03 & .03 & -.05 & -.04 & .03 & -.05 \\
Hope W3 & & & -.49 & .04 & $-.51^{* * *}$ & -.50 & .04 & $-.52^{* * *}$ \\
Interaction & & & & & & -.07 & .04 & .06 \\
\hline$\Delta R^{2}$ & & & $.10^{* * *}$ & & & $.26^{* * *}$ & & & .00 \\
\hline
\end{tabular}

Note. $\mathrm{FD}=$ financial distress; $\mathrm{PSB}=$ prosocial behavior; $\mathrm{W}=$ Wave. Hope was reverse scored. $* p<.05, * * p<.01, * * * p<.001$. 
DOES HOPE MODERATE THE EFFECTS OF FINANCIAL DISTRESS

Table F2

Multiple Regression Analysis on Anxiety without SES

\begin{tabular}{|c|c|c|c|c|c|c|c|c|c|}
\hline & \multicolumn{3}{|c|}{1} & \multicolumn{3}{|c|}{2} & \multicolumn{3}{|c|}{3} \\
\hline Variable & $B$ & $S E B$ & $\beta$ & $B$ & $S E B$ & $\beta$ & $B$ & $S E B$ & $\beta$ \\
\hline Sex & -.21 & .06 & $-.18 * * *$ & -.22 & .06 & $-.18 * * *$ & -.22 & .06 & $-.19 * * *$ \\
\hline African American & .09 & .08 & .05 & .05 & .09 & .03 & .06 & .09 & .03 \\
\hline All Other Ethnicities & .01 & .07 & .01 & .01 & .07 & .01 & .01 & .07 & .01 \\
\hline Child Age & .05 & .03 & .08 & .03 & .03 & .06 & .04 & .03 & .06 \\
\hline FD W3 & & & & .10 & .03 & $.13 * *$ & .09 & .03 & $.13 *$ \\
\hline Hope W3 & & & & .07 & .04 & .08 & .07 & .04 & .07 \\
\hline Interaction & & & & & & & .09 & .05 & .09 \\
\hline$\Delta R^{2}$ & & & $.04 * * *$ & & & $.02 * *$ & & & .01 \\
\hline
\end{tabular}

Note. $\mathrm{FD}=$ financial distress; $\mathrm{PSB}=$ prosocial behavior; $\mathrm{W}=$ Wave. Hope was reverse scored. $* p<.05, * * p<.01, * * * p<.001$. 
DOES HOPE MODERATE THE EFFECTS OF FINANCIAL DISTRESS

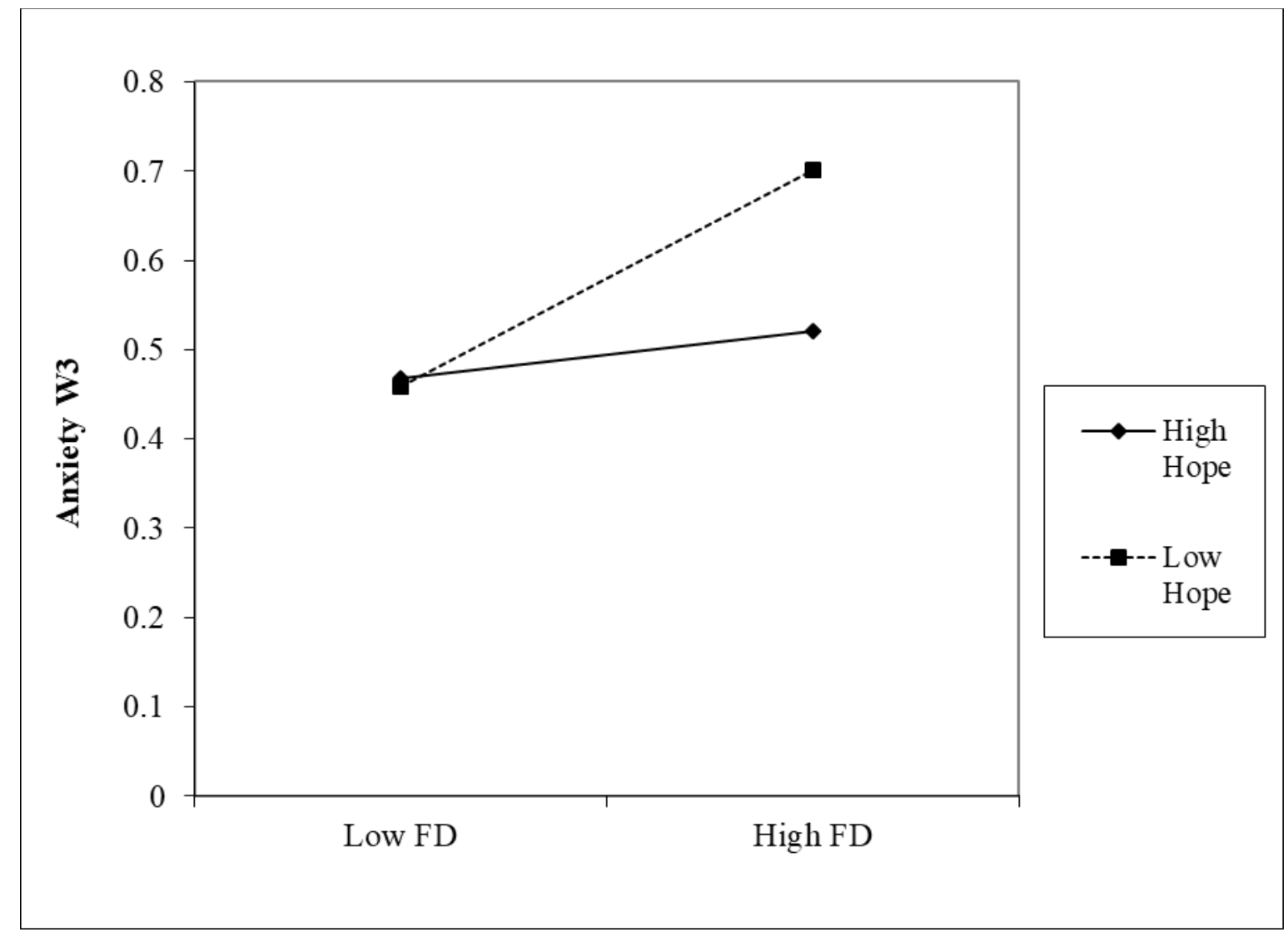

Figure F1. Moderation of hope on financial distress and anxiety. High hope SS $=.03, t(4,444)=1.08, p=.28$. Low hope SS $=.05$, $t(4,444)=4.97, p<.001$ 
DOES HOPE MODERATE THE EFFECTS OF FINANCIAL DISTRESS

\section{Table 1}

Descriptive Statistics

\begin{tabular}{llll}
\hline Variable & $N$ & $M(S D) / \%$ & Range \\
\hline Male Sex & 478 & $46 \%$ & \\
African American & 483 & $12.4 \%$ & \\
All Other Ethnicities & 459 & $29.4 \%$ & $11.00-16.00$ \\
Child Age & 459 & $13.32(1.05)$ & $1.00-12.00$ \\
Parent Income (SES) & 354 & $8.17(3.14)$ & $1.00-4.91$ \\
FD W3 & 460 & $2.36(.84)$ & $1.00-4.60$ \\
Hope W3 & 459 & $2.28(.65)$ & $1.50-4.94$ \\
PSB W3 & 459 & $3.68(.62)$ & $1.89-5.00$ \\
PSB W5 & 465 & $3.81(.58)$ & $0.00-3.00$ \\
Anxiety W3 & 459 & $.89(.59)$ & $0.00-3.00$ \\
Anxiety W5 & 465 & $.97(.59)$ &
\end{tabular}


DOES HOPE MODERATE THE EFFECTS OF FINANCIAL DISTRESS

\section{Table 2}

Bivariate Correlations

\begin{tabular}{|c|c|c|c|c|c|c|c|c|c|c|}
\hline Variable & 1 & 2 & 3 & 4 & 5 & 6 & 7 & 8 & 9 & 10 \\
\hline 1. Sex & & & & & & & & & & \\
\hline 2. African American & -.01 & & & & & & & & & \\
\hline 3. All Other Ethnicities & -.01 & $-.18 * *$ & & & & & & & & \\
\hline 4. Child Age & .04 & .06 & -.03 & & & & & & & \\
\hline 5. SES & .03 & $-.23 * *$ & -.07 & -.04 & & & & & & \\
\hline 6. FD W3 & -.01 & $.26^{* *}$ & -.05 & $.11^{*}$ & $-.56 * *$ & & & & & \\
\hline 7. Hope W3 & .06 & $-.14 * *$ & .03 & $.11^{*}$ & .01 & .00 & & & & \\
\hline 8. PSB W3 & $-.29 * *$ & $-.10^{*}$ & -.07 & $-.10 *$ & .03 & $-.09 *$ & $-.50 * *$ & & & \\
\hline 9. PSB W5 & $-.28 * *$ & $-.18 * *$ & -.06 & -.04 & .00 & -.05 & $-.35 * *$ & $.66 * *$ & & \\
\hline 10. Anxiety W3 & $-.18 * *$ & .06 & -.01 & .06 & $-.11 *$ & $.14 * *$ & .07 & $.12 *$ & $.14 * *$ & \\
\hline 11. Anxiety W5 & $-.24 * *$ & -.03 & .01 & .00 & .00 & .08 & -.01 & $.18 * *$ & $.17 * *$ & $.53 * *$ \\
\hline
\end{tabular}


DOES HOPE MODERATE THE EFFECTS OF FINANCIAL DISTRESS

\section{Table 3}

Multiple Regression Analysis on Prosocial Behavior Without SES

\begin{tabular}{|c|c|c|c|c|c|c|c|c|c|c|c|c|}
\hline & \multicolumn{3}{|c|}{1} & \multicolumn{3}{|c|}{2} & \multicolumn{3}{|c|}{3} & \multicolumn{3}{|c|}{4} \\
\hline Variable & $B$ & $S E B$ & $\beta$ & $B$ & $S E B$ & $\beta$ & $B$ & $S E B$ & $\beta$ & $B$ & $S E B$ & $\beta$ \\
\hline Sex & -.33 & .05 & $-.29 * * *$ & -.31 & .05 & $-.27 * * *$ & -.31 & .05 & $-.27 * * *$ & -.13 & .04 & $-.11 * *$ \\
\hline African American & -.35 & .08 & $-.20 * * *$ & -.44 & .08 & $-.25 * * *$ & -.44 & .08 & $-.25 * * *$ & -.26 & .07 & $-.15 * * *$ \\
\hline All Other Ethnicities & -.12 & .07 & -.08 & -.12 & .07 & -.08 & -.12 & .07 & -.08 & -.04 & .05 & -.03 \\
\hline Child Age & -.01 & .03 & -.01 & .01 & .02 & .03 & .01 & .02 & .03 & .02 & .02 & .04 \\
\hline FD W3 & & & & .01 & .03 & .02 & .01 & .03 & .02 & .03 & .03 & .05 \\
\hline Hope W3 & & & & -.34 & .04 & $-.38 * * *$ & -.34 & .04 & $-.38 * * *$ & -.07 & .04 & -.08 \\
\hline Interaction & & & & & & & .00 & .04 & .00 & -.05 & .04 & -.05 \\
\hline PSB W3 & & & & & & & & & & .55 & .04 & $.58 * * *$ \\
\hline$\Delta R^{2}$ & & & $.12 * * *$ & & & $.14 * * *$ & & & .01 & & & $.21 * * *$ \\
\hline
\end{tabular}

Note. $\mathrm{FD}=$ financial distress; $\mathrm{PSB}=$ prosocial behavior; $\mathrm{W}=$ Wave. Hope was reverse scored. $* p<.05, * * p<.01, * * * p<.001$. 
DOES HOPE MODERATE THE EFFECTS OF FINANCIAL DISTRESS

\section{Table 4}

Multiple Regression Analysis on Anxiety Without SES

\begin{tabular}{|c|c|c|c|c|c|c|c|c|c|c|c|c|}
\hline & \multicolumn{3}{|c|}{1} & \multicolumn{3}{|c|}{2} & \multicolumn{3}{|c|}{3} & \multicolumn{3}{|c|}{4} \\
\hline Variable & $B$ & $S E B$ & $\beta$ & $B$ & $S E B$ & $\beta$ & $B$ & $S E B$ & $\beta$ & $B$ & $S E B$ & $\beta$ \\
\hline Sex & -.29 & .06 & $-.24 * * *$ & -.29 & .36 & $-.24 * * *$ & -.29 & .06 & $-.24 * * *$ & -.17 & .05 & $-.14 * *$ \\
\hline African American & -.04 & .09 & -.02 & -.08 & .06 & -.04 & -.08 & .09 & -.04 & -.11 & .07 & -.06 \\
\hline All Other Ethnicities & .00 & .08 & .00 & .00 & .09 & .00 & .00 & .08 & .00 & -.01 & .06 & -.01 \\
\hline Child Age & .01 & .03 & .02 & .01 & .07 & .01 & .01 & .03 & .01 & -.01 & .02 & -.02 \\
\hline FD W3 & & & & .06 & .03 & .09 & .06 & .04 & .09 & .01 & .03 & .02 \\
\hline Hope W3 & & & & .00 & .04 & .00 & .00 & .05 & .00 & -.03 & .04 & -.03 \\
\hline Interaction & & & & & & & .01 & .05 & .01 & -.04 & .04 & -.04 \\
\hline Anxiety W3 & & & & & & & & & & .52 & .04 & $.52 * * *$ \\
\hline$\Delta R^{2}$ & & & $.06 * * *$ & & & .01 & & & .00 & & & $.25 * * *$ \\
\hline
\end{tabular}

Note. $\mathrm{FD}=$ financial distress; $\mathrm{PSB}=$ prosocial behavior; $\mathrm{W}=$ Wave. Hope was reverse scored. $* p<.05, * * p<.01, * * * p<.001$. 
DOES HOPE MODERATE THE EFFECTS OF FINANCIAL DISTRESS
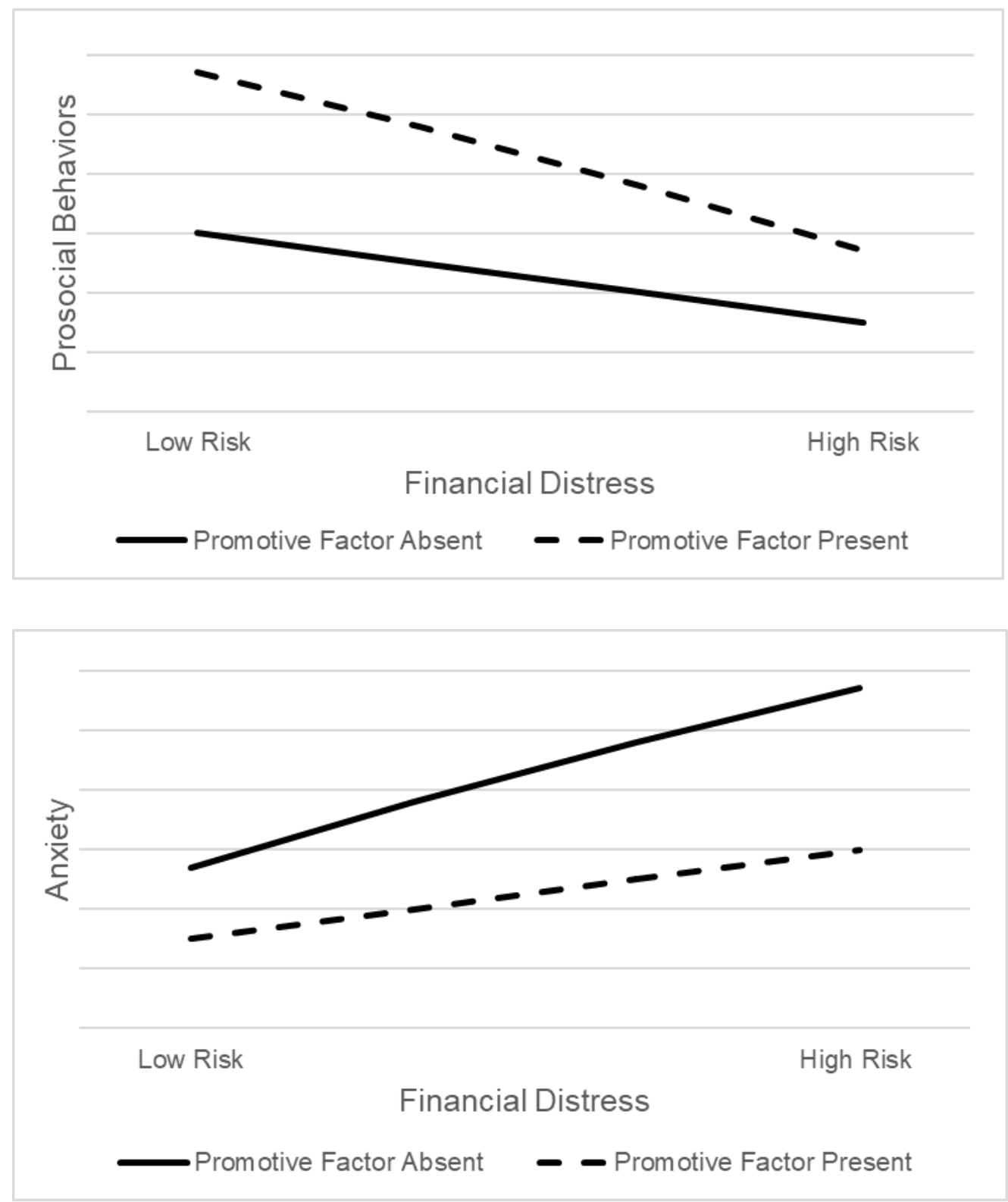

Figures $1 a-b$. The Protective Reactive Model for a positive outcome and a negative outcome (Fergus \& Zimmerman, 2005). 